\title{
Geographic Origin Determination Of AleXANDRITE
}

Ziyin Sun, Aaron C. Palke, Jonathan Muyal, Dino DeGhionno, and Shane F. McClure

The gem and jewelry trade has come to place increasing importance on the geographic origin of alexandrite, as it can have a significant impact on value. Alexandrites from Russia and Brazil are usually more highly valued than those from other countries. In 2016, GIA began researching geographic origin of alexandrite with the intent of offering origin determination as a laboratory service. Unfortunately, collecting reliable samples with known provenance can be very difficult. Alexandrite is often recovered as a byproduct of mining for other gemstones (e.g., emerald and corundum), so it can be difficult to secure reliable parcels of samples because production is typically erratic and unpredictable. The reference materials studied here were examined thoroughly for their trace element chemistry profiles, characteristic color-change ranges under daylight-equivalent and incandescent illumination, and inclusion scenes. The data obtained so far allow us to accurately determine geographic origin for alexandrites from Russia, Brazil, Sri Lanka, Tanzania, and India. Future work may help to differentiate alexandrites from other localities.

A fter the discovery of a gem mineral with unusual color-change behavior in the Russian Ural Mountains during the early 1830s, Swedish mineralogist Nils Adolf Erik Nordenskiöld named this new gem alexandrite in 1834 in honor of the future Czar Alexander II (Kozlov, 2005). This immediately created a royal and romantic aura around this variety of chrysoberyl. The most coveted alexandrites exhibit a lush green to greenish blue color in daylight and a warm, bright red shade in candlelight (Levine, 2008); some fine Brazilian and Indian alexandrite examples are shown in figures 1-3 and 6. This phenomenal color change is caused by the presence of trace $\mathrm{Cr}^{3+}$ substituting for $\mathrm{Al}^{3+}$ in the chrysoberyl crystal structure. Alexandrite is routinely described as "emerald by day, ruby by night." It is a stone of duality-green or red, cool or warm, day or night (Levine, 2008). Because of its rare and attractive color-change phenomenon, alexandrite has been highly sought after and is one of the most valuable gemstones in the trade.

Alexandrite, particularly fine-quality material, is also very scarce; it has generally been a byproduct of

See end of article for About the Authors and Acknowledgments.

Gems \& Gemology, Vol. 55, No. 4, pp. 660-681,

http://dx.doi.org/10.5741/GEMS.55.4.660

(C) 2019 Gemological Institute of America mining other major colored stones. Overall production statistics are hard to evaluate. It has been mined in Russia (Kozlov, 2005; Schmetzer, 2010), Tanzania

\section{In Brief}

- Geographic origin can significantly affect alexandrite's value.

- Collecting reliable alexandrite samples with known provenance can be very difficult because production is typically erratic and unpredictable.

- Trace element chemistry data obtained from LA-ICPMS are the primary consideration in determining its geographic origin.

- Color-change behavior and inclusions are used as secondary factors to support the geographic origin determination.

(Gübelin, 1976; Schmetzer and Malsy, 2011b) and Zimbabwe (Brown and Kelly, 1984; Schmetzer et al., 2011) as a byproduct of emerald mining, and in Brazil (Proctor, 1988; Cassedanne and Roditi, 1993; Voynick, 1988) and India (Newlay and Pashine, 1993; Patnaik and Nayak, 1993; Panjikar and Ramchandran,1997; Voynick, 1988; Valentini, 1998) along with cat's-eye and nonphenomenal chrysoberyl, as 

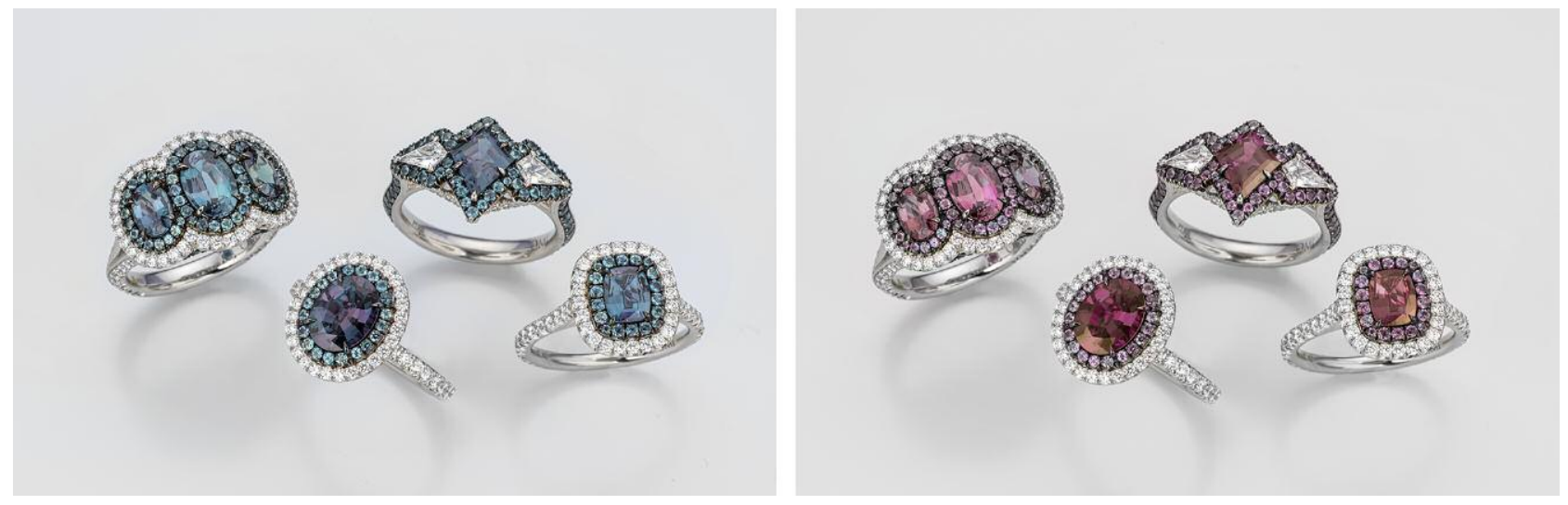

Figure 1. A group of rings featuring alexandrite from Brazil. Top row, left to right: A three-stone alexandrite ring with a 1.35 ct center oval flanked by two smaller ovals with a combined weight of 1.29 carats and a ring with a $1.32 \mathrm{ct} \mathrm{kite-shaped} \mathrm{center} \mathrm{stone} \mathrm{flanked} \mathrm{by} \mathrm{two} \mathrm{kite-shaped} \mathrm{diamonds} \mathrm{weighing} \mathrm{a} \mathrm{total} \mathrm{of} 0.32$ carats. Bottom row, left to right: Rings featuring a $1.71 \mathrm{ct}$ oval and a $0.72 \mathrm{ct}$ cushion-cut alexandrite. The designs also feature melee-cut alexandrites of unknown provenance and diamonds. The image on the left was photographed in daylight-equivalent lighting, the image on the right in incandescent light. Detailed procedures for photographing the alexandrites shown in this article are provided in appendixes 2 and 3, online at https://www.gia.edu/doc/WN19-AlexandriteAppendixes2-3.pdf. Photos by Robert Weldon/GIA; courtesy of Omi Privé.

well as other pegmatitic minerals. In Sri Lanka (Zwaan, 1982; Zoysa, 1987, 2014), it is mined as a byproduct of corundum, cat's-eye and nonphenomenal chrysoberyl, and other minerals. The supply of alexandrite in the U.S. market has been low since the 1990s, as the supplies from the initial rush in Brazil presumably started drying up (Costanza, 1998). However, demand for the gemstone has stayed high in the U.S., especially for large stones with high clarity and intense and distinctive color change (again, see figures 1-3 and 6). The situation has changed somewhat recently, with new production from Sri Lanka, Brazil, and Tanzania (Jarrett, 2015).

With the development of these modern sources and the subsequent rapid changes in the alexandrite supply chain, there is growing demand from the gem trade for geographic origin determination for fine alexandrite. Origin is increasingly important, as it is often used as a factor in establishing a stone's value. Stones from Russia or Brazil can easily command a higher price than alexandrite from Tanzania and Zimbabwe with the same attributes. Because of all of

Figure 2. This ring features a $0.72 \mathrm{ct}$ Brazilian cushion-cut alexandrite with a strong color-change effect, and the design uses additional alexandrite melee and diamonds as accents. The loose oval alexandrite below the ring weighs $4.13 \mathrm{ct}$ and hails from India. The image on the left was photographed in daylight-equivalent lighting, the image on the right in incandescent light. Photos by Robert Weldon/GIA; courtesy of Omi Privé.

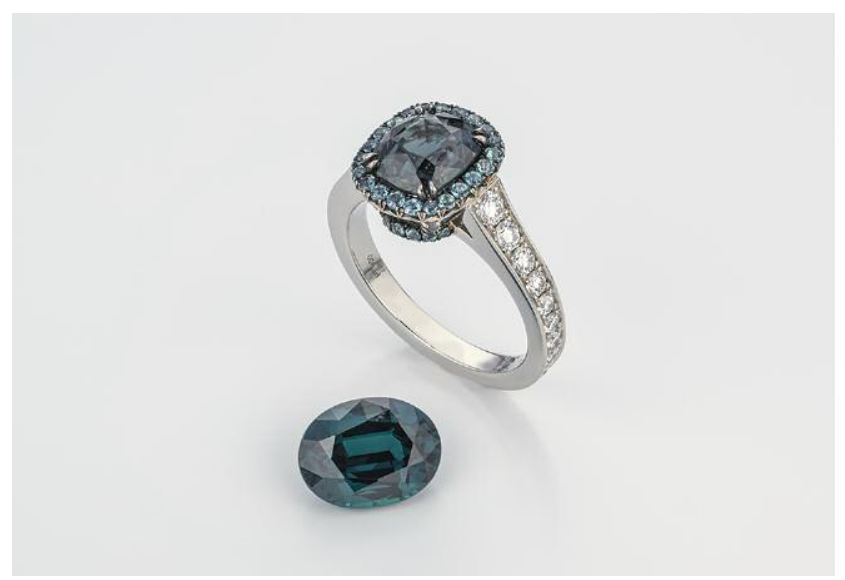



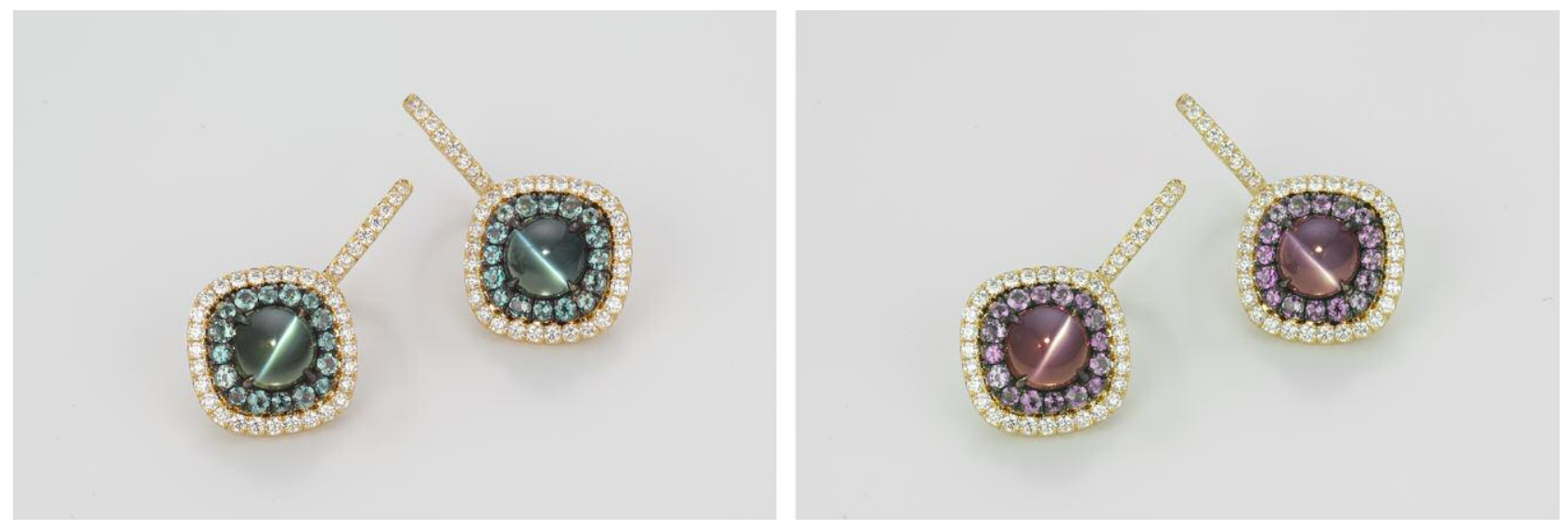

Figure 3. This matched pair of cat's-eye alexandrites from Brazil exhibits double phenomena (color change and chatoyancy) and weighs a total of 2.43 carats. The design also features alexandrite and diamond melee accents. The image on the left was photographed with daylight-equivalent lighting and the image on the right with incandescent light. Pinpoint light was used to reveal the stones' chatoyancy. Photos by Robert Weldon/GIA; courtesy of Omi Privé.

these market factors, in 2016 GIA initiated a research project centered around alexandrite geographic origin determination. Since then, many samples have gone through the laboratories and had their characteristic chemistry, colors, and inclusions carefully documented. Reference stones with reliable provenance were obtained from multiple sources. The data collected on stones from a single country from various sources were generally found to be self-consistent, which corroborates the validity of the origin determination criteria developed. GIA announced the origin determination service in early 2019 and will continue to develop its alexandrite database to ensure the most accurate identification and origin reporting for the jewelry trade.

\section{ALEXANDRITE GEOGRAPHIC LOCALITIES: A BRIEF SUMMARY}

Russia. The original locality for alexandrite remains one of the most highly valued sources (Kozlov, 2005; Schmetzer, 2010). Alexandrites from Russia are generally a byproduct of emerald mining from metamorphic mica-schist veins in ultramafic host rocks. The micaceous rocks are called "glimmerites" because of the glowing sheen of the micas.

Russian production began in the 1830s but waned in the twentieth century when mining emphasis shifted to beryllium, and it lapsed with the fall of the Soviet Union in 1991. Recent efforts have been undertaken to increase Russian alexandrite production.
There are a few important deposits: Mariinskoye (Malyshevskoye); Cheremshanskoye; Sretenskoye (Sverdlovskoye), where the first Russian emeralds were discovered; Krasnobolotnoye, where the largest and most beautiful Russian alexandrites were found in 1839; and Krasnoarmeiskoye. Of these, the Mariinskoye deposit has historically had the largest mining operation.

Sri Lanka. Sri Lanka is one of the world's most important gemstone localities (Zwaan, 1982; Zoysa, $1987,2014)$. The main gem-bearing areas are the Ratnapura district in Sabaragamuwa Province, Elahera in Central Province, Okkampitiya in Uva Province, and the Kataragama area in Southern Province. The chrysoberyl occurrences are more frequently found in and around Morawaka and Deniyaya in Southern Province. All of these gems occur in alluvial deposits underlain by Precambrian metamorphic rocks, and their original source remains unknown. There was little reliable information available on the amount and value of the gem material recovered in Sri Lanka until 1923, when the discovery of fine-quality alexandrites in Ratnapura's Pelmadulla deposits was reported. There was a constant supply of Sri Lankan alexandrite in the market until the end of the 1980s, when production dropped (Proctor, 1988).

Most Sri Lankan alexandrites have a weaker color change than Russian and Brazilian stones (see the loose stones in figure 4), although finer-quality material can show color change from saturated green to 

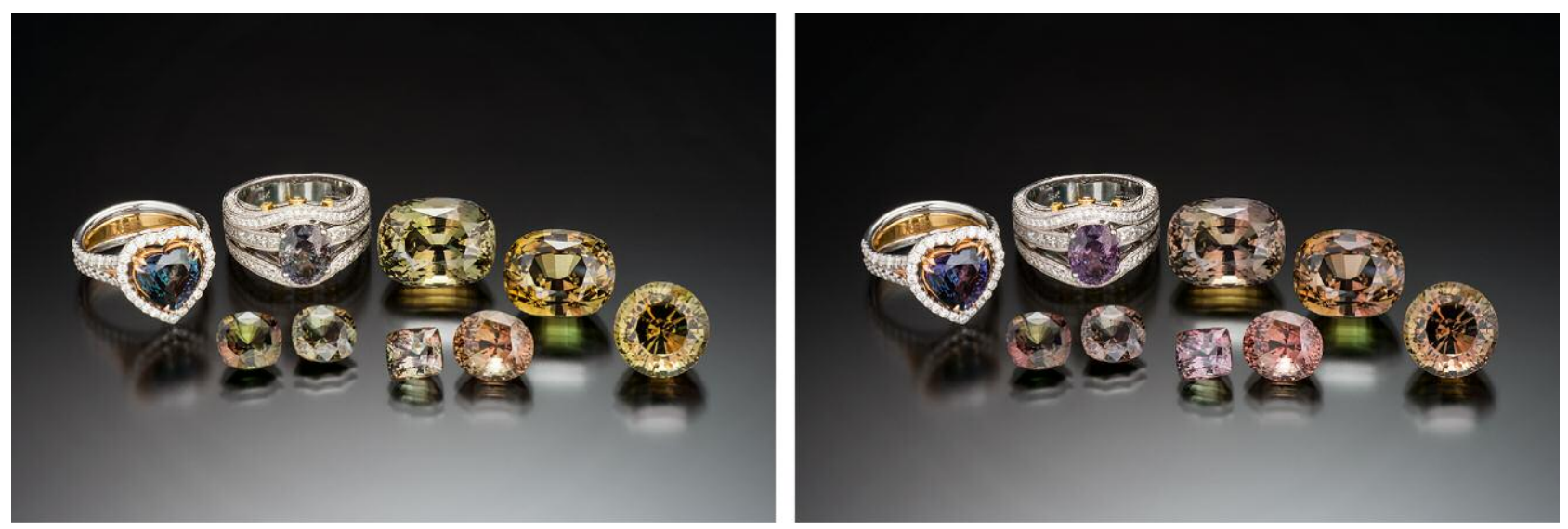

Figure 4. The ring on the far left features a heart-shaped alexandrite from India. The second ring is mounted with an oval-shaped alexandrite_possibly from Madagascar-and melee-cut diamonds. All loose faceted stones are from Sri Lanka. The stones range from 4.01 to $22.99 \mathrm{ct}$. The image on the left was taken under an LED light source simulating daylight-equivalent lighting, while the right-hand image was taken under an LED light source simulating incandescent illumination. Photos by Kevin Schumacher; courtesy of LC Gem Collection Inc.

red. However, Sri Lankan alexandrites often achieve large sizes with high clarity, and stones up to $600 \mathrm{ct}$ have been examined by GIA.

Brazil. In the 1980s, as Russia's Uralian deposits were producing little and supplies from Sri Lanka were drying up, the pegmatite district in Minas Gerais, Brazil, became for a time the world's major alexandrite producer (Koivula, 1987a,b; Proctor, 1988; Cassedanne and Roditi, 1993).

From 1846 until the 1980s, the Americana and Santana Valleys, near the city of Padre Paraíso in the Teófilo Otoni-Marambaia pegmatite districts, accounted for approximately $95 \%$ of the chrysoberyl and cat's-eye chrysoberyl found in Minas Gerais. But fine alexandrites from the Americana, Santana, Gil, and Barro Preto Valleys were rare. Brazil's foremost source of fine alexandrite was the Malacacheta region in the northeast of Minas Gerais State. Alexandrite was mined there from 1975 to 1988, with peak production in the early 1980s. In 1987, the Lavra de Hematita alexandrite deposit was discovered. This marked the greatest discovery of Brazilian alexandrite. To date, Hematita has yielded tens of kilos of alexandrite that are generally larger and cleaner than those from Malacacheta, including some faceted gems weighing up to $30 \mathrm{ct}$ that exhibit extraordinary color change. A few locations in the adjacent states of Bahia and Espírito Santo also produce alexandrite, albeit with an overall lower quality in terms of color, clarity, size, or some combination.
Most of the finest cyclical twinned alexandrite mineral specimens in today's market come from Brazil (see figure 5). Brazilian alexandrites have a distinct color change that is often comparable to that of the finest Russian stones (see figure 6), but with a higher clarity, larger size, and much greater availability. Brazil also produces some of the world's finest cat's-eye alexandrite, such as the pair in figure 3 that exhibit a distinct color change and a sharp eye.

India. In the religions associated with Southeast Asia and the Indian subcontinent-Hinduism, Jainism, and Buddhism-cat's-eye chrysoberyl holds a place of distinction among the Navratnas (a combination of nine sacred gemstones) (Brunel, 1972). Chrysoberyl has been mined in five Indian states-Kerala, Madhya Pradesh, Odisha (formerly Orissa), Andhra Pradesh, and Tamil Nadu-since the 1980s and '90s. Alexandrite is found there either in pegmatites intruding granitic rock or in biotite schists developed along the contact zone of pegmatites and peridotites (Soman and Nair, 1985; Patnaik and Nayak, 1993; Newlay and Pashine, 1993; Panjikar and Ramchandran, 1997; Valentini, 1998).

Indian alexandrites usually have a weaker color change than Russian and Brazilian material (see the ring mounted with a heart-shaped stone in figure 4). However, stones with good color change and clarity are comparable to the finest Russian and Brazilian specimens. The $4.13 \mathrm{ct}$ loose oval in figure 2 , repre- 

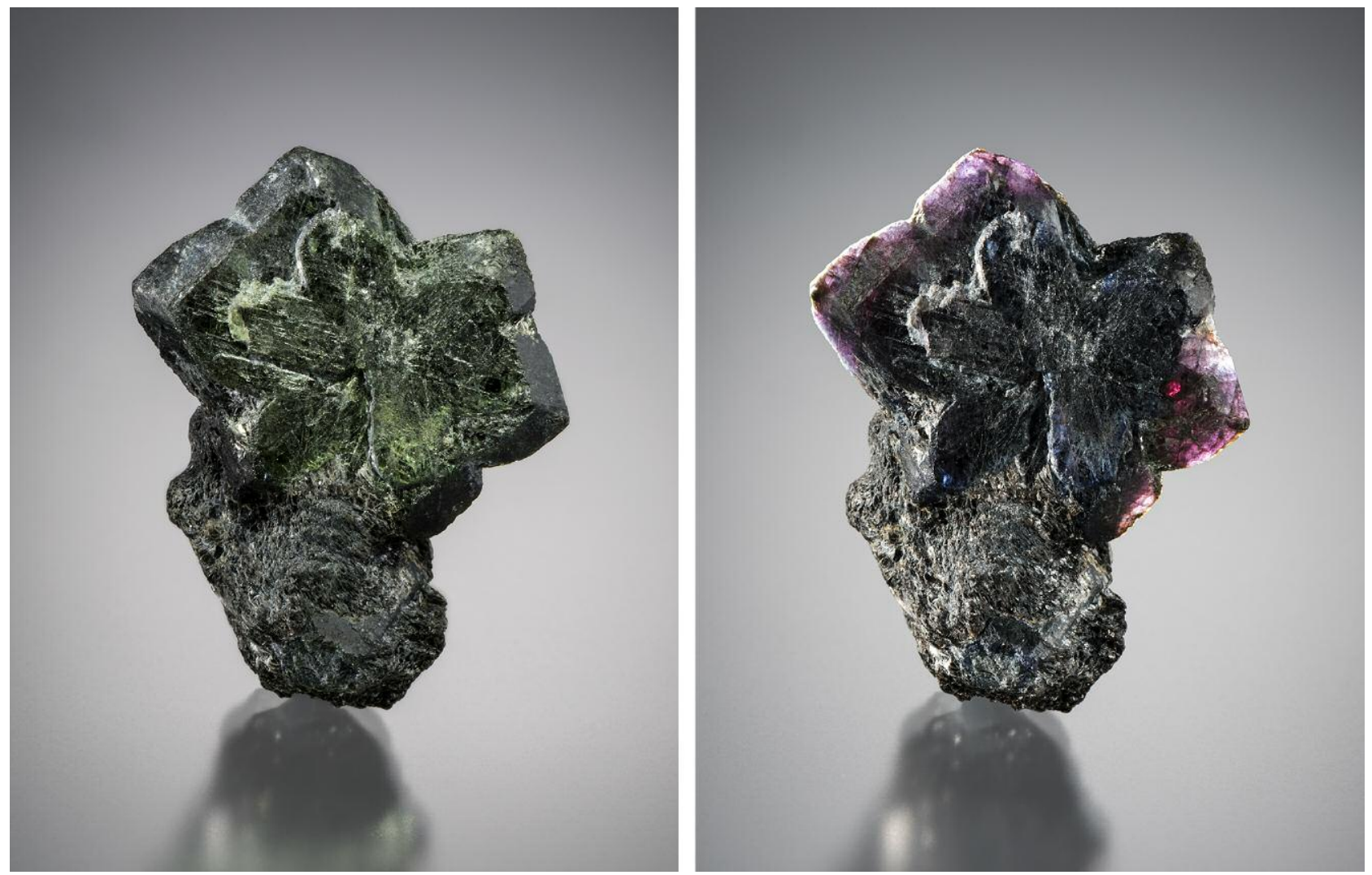

Figure 5. A cyclical twinned Brazilian alexandrite mineral specimen, $4.13 \mathrm{~cm}$ in the longest dimension, shows distinct color change from green to red under daylight-equivalent lighting and incandescent illumination, respectively. The image on the left was taken under an LED light source simulating daylight-equivalent lighting, while the image on the right was taken under an LED light source simulating incandescent illumination. Photos by Kevin Schumacher; courtesy of John I. Koivula.

senting top-quality Indian alexandrite, exhibited saturated blue-green color under daylight and saturated red under incandescent light. Many small Indian cat's-eye alexandrites with weak color change are fairly common in today's market, but Indian cat'seye alexandrite with distinct color change and sharp eyes are rare.

Tanzania. Alexandrite has come mainly from two mining areas in Tanzania: Lake Manyara in the north and Tunduru in the south (Gübelin, 1976; Johnson and Koivula, 1996, 1997; Henricus, 2001; Schmetzer and Malsy, 2011b; Jarrett, 2015). Lake Manyara is a primary deposit where alexandrite has been found in a phlogopite-bearing schist. Alexandrite from Tunduru has been mined from a secondary alluvial deposit. Alexandrite from Lake Manyara (figure 7) entered the market in the 1960s, with significant production into the early 1980s. Johnson and Koivula reported a wide variety of gem materi- als, including alexandrite, from Tunduru at the Tucson show in 1996. Since then, the area has been known for producing large quantities of alexandrite, and material from Tunduru was available in the U.S. market in 2015 according to Michael Couch of Michael Couch \& Associates (Jarrett, 2015). In the early 2000s, emerald and alexandrite were reported from Mayoka, just outside Manyara National Park, by Abe Suleman, a director of the International Colored Gemstone Association and a member of the Tanzania Mineral Dealers Association (Henricus, 2001), but environmental concerns stopped mining activities in late 2000 and little material was produced.

A chameleon brooch mounted with beautiful rough alexandrite crystals from Lake Manyara on its back and small faceted alexandrites on its legs and tail changes from blue green to violet when viewing under daylight and incandescent light, as seen in figure 7. 

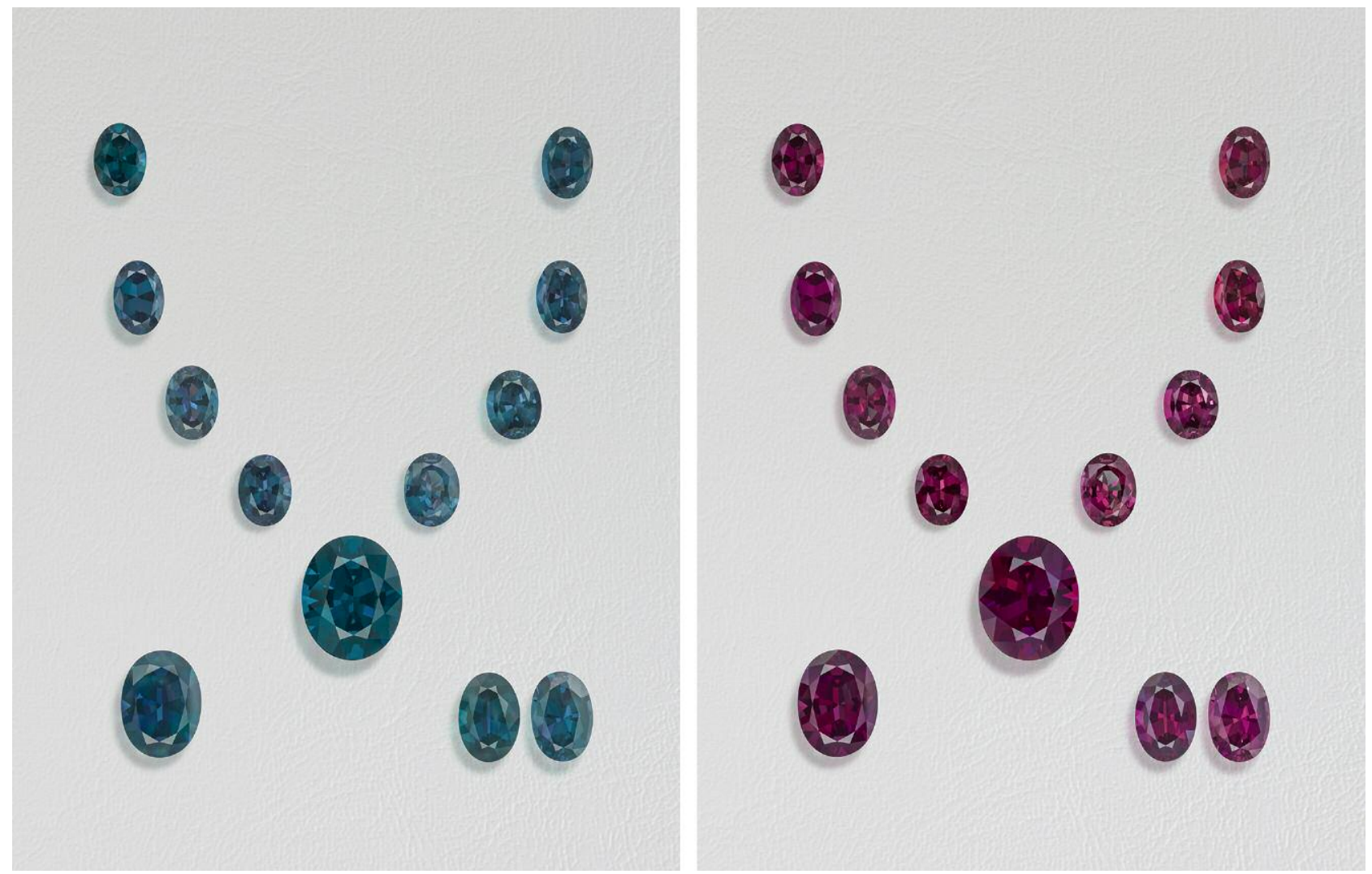

Figure 6. A suite of fine Brazilian alexandrite exhibiting the finest color change seen in this material. The left image was taken under an LED light source simulating daylight-equivalent lighting, while the right photo was taken under an LED light source simulating incandescent illumination. Photos by Robert Weldon/GIA; courtesy of Evan Caplan.

Minor Alexandrite Geographic Localities. Zimbabwe. Alexandrite has been recovered from the Novello deposit of Zimbabwe's Masvingo district (Schmetzer, 2011). It is located in a phlogopite-bearing host rock with surrounding serpentinite. Peak production was in the 1960s and 1970s and yielded larger, mostly nonfacet-grade material. The material is considered very dark and only suitable for faceting small stones with

Figure 7. Rough and faceted alexandrite from Lake Manyara, Tanzania. The left image was taken under an LED light source simulating daylight-equivalent lighting, while the right photo was taken under an LED light source simulating incandescent illumination. Photos by Robert Weldon/GIA; courtesy of Omi Privé.
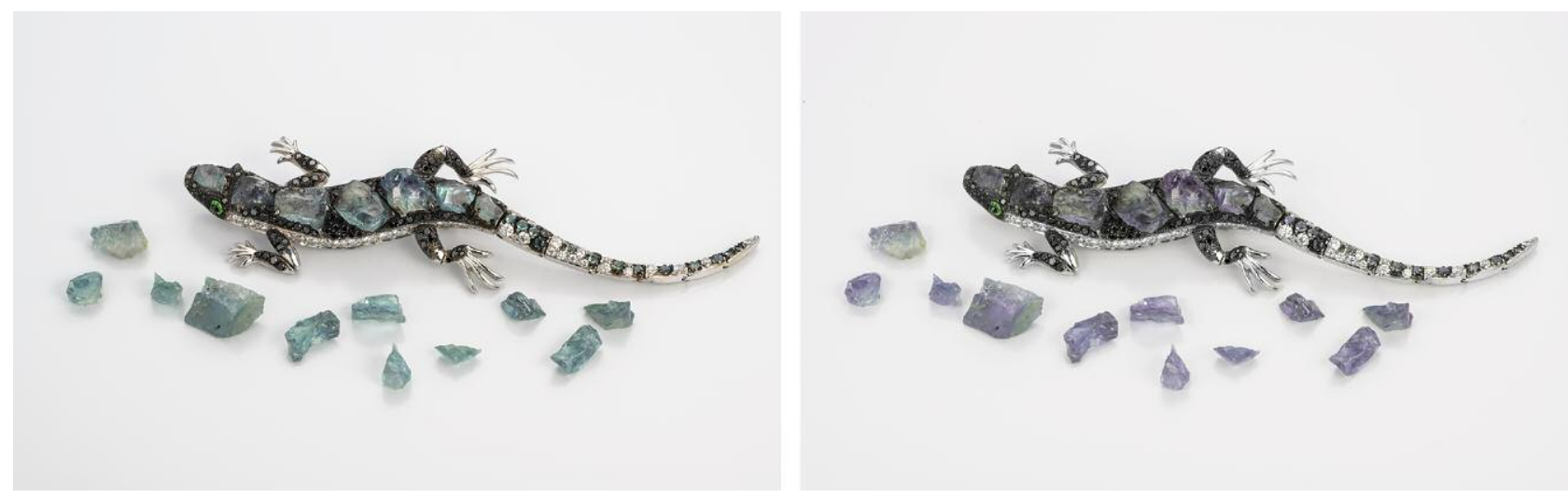
intense color change. The deposit is believed to still produce alexandrite.

Madagascar. Alexandrite originating from phlogopite-bearing host rocks comes from primary emerald deposits in the Mananjary region of Madagascar (Schmetzer and Malsy, 2011a). The other deposit, in the Ilakaka region (Hänni, 1999; Milisenda et al., 2001), is a secondary deposit where different varieties of chrysoberyl-including alexandrite-have been found. Occasionally, large alexandrite crystals of gem quality have been recovered in the Lake Alaotra region.

Myanmar. In Myanmar (formerly Burma), the pegmatites in the western part of the Mogok Valley in Sakangyi or Barnardmyo, and the alluvial placers in the Mogok Stone Tract near Mogok, Kyatpyin, and Barnardmyo, have produced gem-quality alexandrite ("Alexandrite world occurrences...," n.d.). Burmese alexandrites usually fluoresce intense red under longand short-wave UV radiation due to lack of iron.

Australia. Dowerin is the first recorded alexandrite occurrence in Western Australia, known since 1930. The deposit has yielded many small crystals (Bevan and Downes, 1997; Downes and Bevan, 2002).

United States. In recent years, small chrysoberyl crystals with weak color change were reported from a mine at La Madera Mountain in Rio Arriba County, New Mexico ("Alexandrite world occurrences \& mining localities," n.d.).

Zambia. Some Zambian alexandrite with similar characteristics to Zimbabwean stones has appeared in the market. No reliable information is currently available.

\section{MATERIALS AND METHODS}

Reference Samples. GIA's research project on alexandrite origin started in early 2016, with suites of alexandrites from both Russia and Brazil. Almost all Russian material came from Warren Boyd, who acquired them as a mining consultant at the Malysheva emerald and alexandrite mine from 1992 to 2007. There are four different sources for the Brazilian alexandrites. Seventeen specimens came from Evan Caplan, who acquired them from a source directly connected to a mine owner in Brazil. Fifteen of the
Brazilian gems came from Nilam Alawdeen, who later provided three Sri Lankan and two Indian stones during this project. Spectrum Fine Jewelry \& Exotic Gems supplied 140 Brazilian alexandrites. Four additional samples came from the GIA Museum. It is very likely that all the Brazilian material came from the Hematita deposit in Minas Gerais.

A few months later, eight Sri Lankan, twenty-one Tanzanian, and two Indian alexandrites were provided to the lab by LC Gem Collection Inc., a Sri Lanka-based gem company. Gem dealer Chandika Thambugala submitted nine Sri Lankan stones to the lab. The GIA Museum was also able to provide thirteen Sri Lankan, four Indian, and five Tanzanian gems. In some cases, all that was known about a specimen was the country of origin; specific mines were unknown. However, the Tanzanian stones were very likely from Lake Manyara. An additional 18 Indian stones were provided by Lance Davidson. Field gemologist Vincent Pardieu provided us with some stones from his personal collection: three Madagascar alexandrites bought in Madagascar; nine Zambian stones bought in Mahesak, Thailand, from a trustworthy source; and one Burmese sample purchased from the trade in Mogok. Five Zimbabwean stones came from two different sources: Two were borrowed from the personal collection of Yusuke Katsurada, a senior gemologist and scientist in GIA's Tokyo laboratory, and the GIA Museum provided the other three. Detailed reference sample provenance is listed in appendix 1, table 1, online at https://www.gia.edu/ doc/WN19-Alexandrite-Appendix1.pdf.

Procedures for Alexandrite Identification in GIA Laboratories. When an alexandrite first arrives at the GIA laboratory, we ask a question even more fundamental than geographic origin: Is this a natural alexandrite? Fourier-transform infrared spectroscopy (FTIR) is performed on every alexandrite to distinguish natural from synthetic material (Stockton and Kane, 1988) and to identify imitations. Natural alexandrites are then sent for laser ablation-inductively coupled plasma-mass spectrometry (LA-ICPMS); see Groat et al. (2019), pp. 512-535 of this issue. This method is used to acquire trace element chemistry for geographic origin determination, if origin service is requested by the client.

After advanced analysis, the stone is given to a preliminary gemologist for standard gemological testing and identification. The stone is examined under a standard GIA desktop microscope for inclu- 
sions that would be indicative of a natural or synthetic origin. Photomicrographs are taken and Raman spectroscopy is performed if there are crystalline inclusions that might aid in origin determination (see Groat et al., 2019, pp. 512-535 of this issue). The colors exhibited by the alexandrite are also considered as possible evidence of origin. A stone's warm and cool colors are also recorded in GIA's database with careful photographic documentation under standardized conditions (see below). The stone is then sent to a more senior gemologist to further check all the physical and chemical properties to confirm the stone's identity and complete the identification and origin determination.

Photography. GIA Digital Imaging for Color-Change Stones. GIA has a set of standardized procedures for photographing color-change stones to ensure consistency in appearance reproduction. The image of an alexandrite is captured using a variety of high-quality cameras and lenses in a specially made light box produced by the GIA instrument department. An LED light with a color temperature around $6500 \mathrm{~K}$ is used as a daylight-equivalent light source, while an LED light with a color temperature around $2700 \mathrm{~K}$ is used as an incandescent light source. The final printed images are viewed in a controlled lighting environment and compared to the actual stone. Slight color adjustments are made with Adobe Photoshop software if needed, using a monitor that is maintained and color calibrated using GretagMacbeth calibration software.

Photomicrography of Inclusions. Photomicrographs are taken using various Nikon microscopes, including an Eclipse LV100, SMZ1500, and SMZ10 (Renfro, $2015 a, b)$. Photographs of the inclusion scenes are captured using Nikon DS-Ri2 digital cameras. Various lighting environments including darkfield, brightfield, and fiber-optic illumination are used to highlight specific internal features. Image stacking (Renfro, 2015a) is sometimes employed to maximize the depth of field of an image.

Raman Spectroscopy. Raman spectra are collected with a Renishaw inVia Raman microscope system. The Raman spectra of the inclusions are collected using a Stellar-REN Modu Ar-ion laser producing highly polarized light at $514 \mathrm{~nm}$ at a nominal resolution of $3 \mathrm{~cm}^{-1}$ in the $2000-200 \mathrm{~cm}^{-1}$ range. Each inclusion spectrum is accumulated three times at $20 x$ or $50 \times$ magnification. In many cases, the confocal ca- pabilities of the Raman system allow inclusions beneath the surface to be analyzed.

FTIR. Fourier-transform infrared spectra are collected using a Thermo Fisher Nicolet 6700 FTIR spectrometer equipped with an XT-KBr beam splitter and a mercury-cadmium-telluride (MCT) detector operating with a $4 \times$ beam condenser accessory. The beam is transmitted through the stone. The spectra are collected at a nominal resolution of $4 \mathrm{~cm}^{-1}$ with $1.928 \mathrm{~cm}^{-1}$ data spacing. Each stone is scanned 128 times to achieve a high signal-to-noise ratio.

LA-ICP-MS. Trace element chemistry is acquired using a Thermo Fisher iCAP Qc ICP-MS coupled with an Elemental Scientific Lasers NWR213 laser ablation system. It incorporates a Nd:YAG laser rod that emits light with a wavelength of $1064 \mathrm{~nm}$ in the infrared and a frequency quintupler system to generate a $213 \mathrm{~nm}(1 / 5$ of $1064 \mathrm{~nm})$ ultraviolet wavelength that is used to ablate samples. Ablation is achieved using a $55 \mu \mathrm{m}$ diameter circular spot size, a fluence (energy density) of approximately $10 \mathrm{~J} / \mathrm{cm}^{2}$, and a 20 $\mathrm{Hz}$ repetition rate. National Institute of Standards and Technology (NIST) Standard Reference Material (SRM) 610 (http://georem.mpch-mainz.gwdg.de/ sample_query.asp; Jochum et al., 2005) is used as an external standard. ${ }^{27} \mathrm{Al}$ is used as an internal standard, with a value of 425000 calculated and rounded from pure chrysoberyl. A similar method was used in works done by Malsy and Schmetzer (Schmetzer, 2010; Schmetzer and Malsy, 2011b; Schmetzer et al., 2011).

\section{RESULTS AND DISCUSSION}

Trace Element Chemistry of Alexandrite from Different Countries. In general, trace element chemistry is the most important factor in determining a geographic origin for alexandrite. By carefully examining our reference datasets, we concluded that $\mathrm{Mg}$, Fe, Ga, $\mathrm{Ge}$, and $\mathrm{Sn}$ are the five best discriminators to distinguish different geographic locations (figure 8). B, V, and $\mathrm{Cr}$ were also good discriminators for separating alexandrites among some countries (see figures 9 and 10), but must be considered as an addition to the first five with specific criteria. The generalized trace element profiles are listed in table 1 . The results described herein and shown in figures $8-10$ are generally consistent with the results previously reported by Malsy and Schmetzer.

Using any two of the five discriminators $(\mathrm{Mg}, \mathrm{Fe}$, 

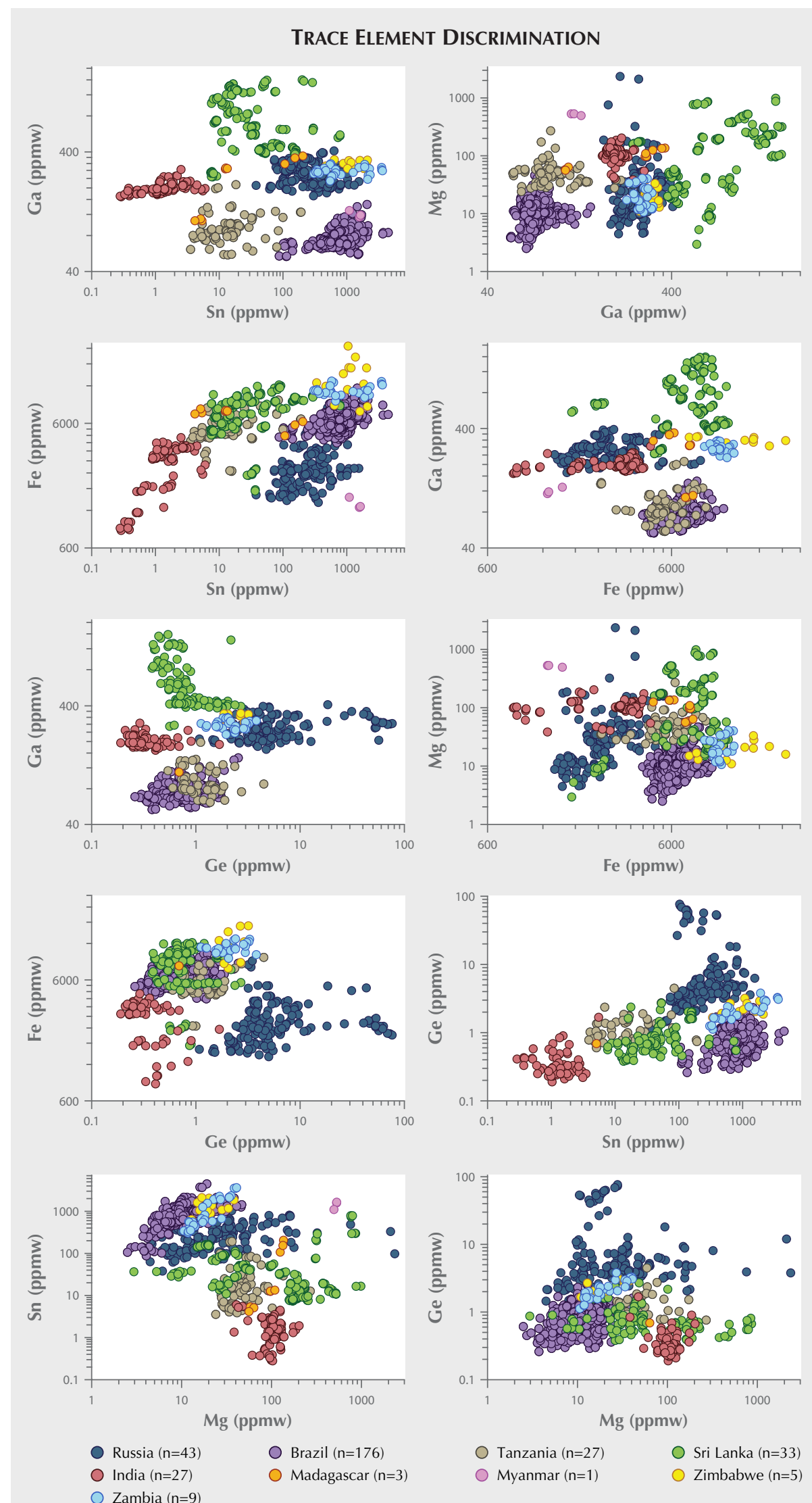
Tanzania $(n=27)$
Sri Lanka $(n=33)$
Myanmar $(n=1)$
Zimbabwe $(n=5)$

Figure 8. Plots of $\mathrm{Mg}$, $\mathrm{Fe}, \mathrm{Ga}, \mathrm{Ge}$, and Sn concentration in alexandrite reference stones from different countries. Ten plots were generated by plotting any two elements against each other. The origin of most alexandrite samples can be confidently ascertained using these 10 plots. 


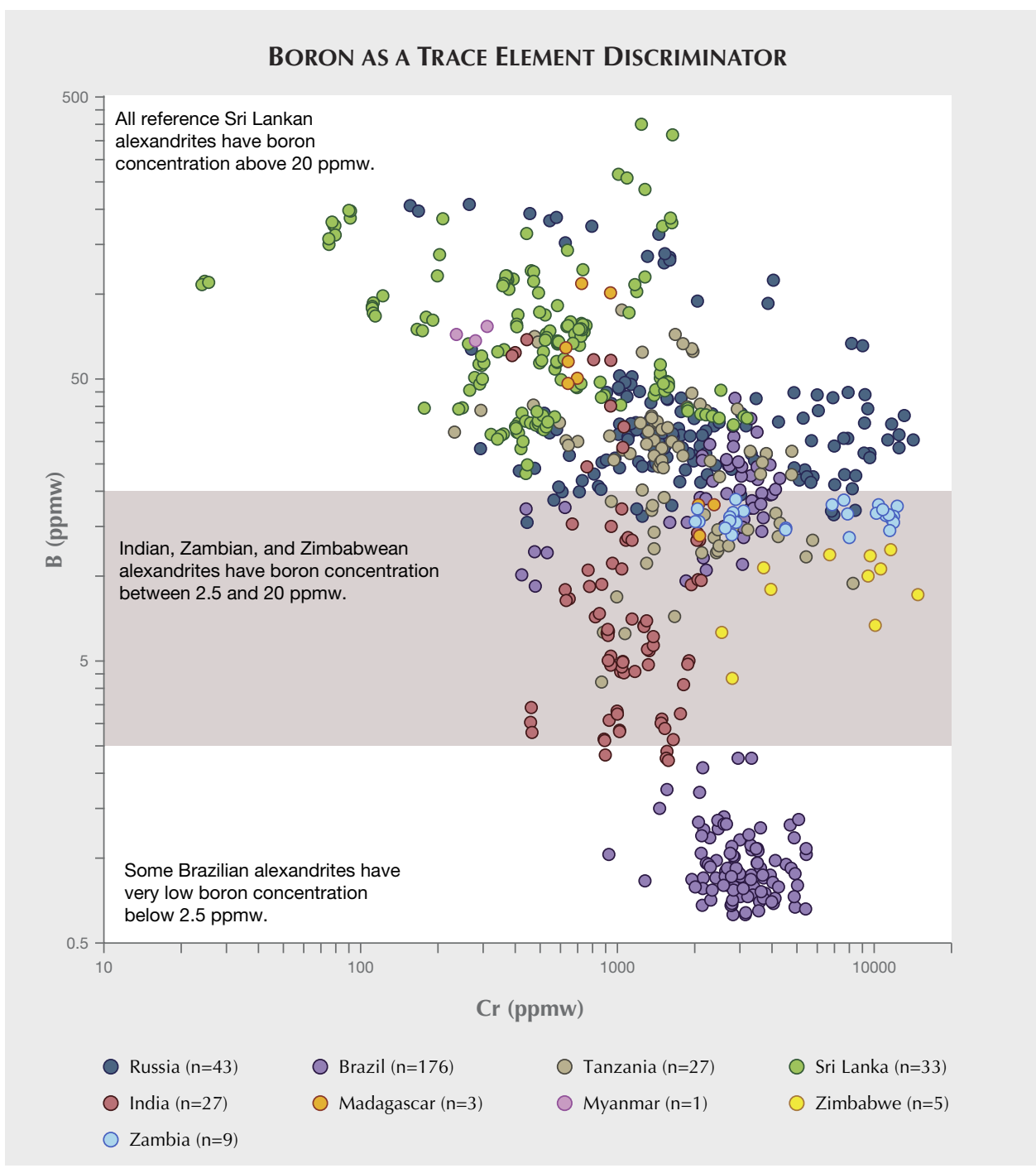

Figure 9. Boron can be used to separate Sri Lankan alexandrite from Indian, Zambian, and Zimbabwean samples. Some Brazilian stones have the lowest boron concentrations among all countries.

$\mathrm{Ga}, \mathrm{Ge}$, and $\mathrm{Sn}$ ) to plot against each other, 10 plots can be generated (figure 8). Alexandrites from different countries have their own characteristic chemistry.

Mg-Indian and Tanzanian alexandrites have high $\mathrm{Mg}$ concentrations, while Brazilian, Zambian, and Zimbabwean stones have low Mg concentration. Russian and Sri Lankan stones have wide ranges of $\mathrm{Mg}$ concentrations that overlap with every other source.

Fe-Zambian and Zimbabwean stones have relatively high Fe concentration, while Tanzanian, Brazilian, and Sri Lankan specimens have medium Fe concentration. Russian and Indian stones have the lowest Fe concentrations.

Ga-Sri Lankan stones have the highest gallium concentration. Indian, Russian, Zambian, and Zim- babwean material falls in a middle range, while Tanzanian and Brazilian alexandrites have the lowest $\mathrm{Ga}$ concentrations.

Ge-Russian alexandrites have the highest germanium concentrations, while Sri Lankan, Indian, Brazilian, and Tanzanian stones have the lowest. Zambian and Zimbabwean stones have medium Ge concentrations.

Sn-Russian, Brazilian, Zambian, and Zimbabwean alexandrites have higher Sn concentrations, while Indian specimens have lower amounts. Sri Lankan and Tanzanian stones have similar Sn concentrations in the middle range.

In addition to these five discriminators, $\mathrm{B}, \mathrm{V}$, and $\mathrm{Cr}$ are very useful for some specific cases. These three elements can further validate geographic origin 
Crvs. V AND V vs. B TRACE Element DisCrimination
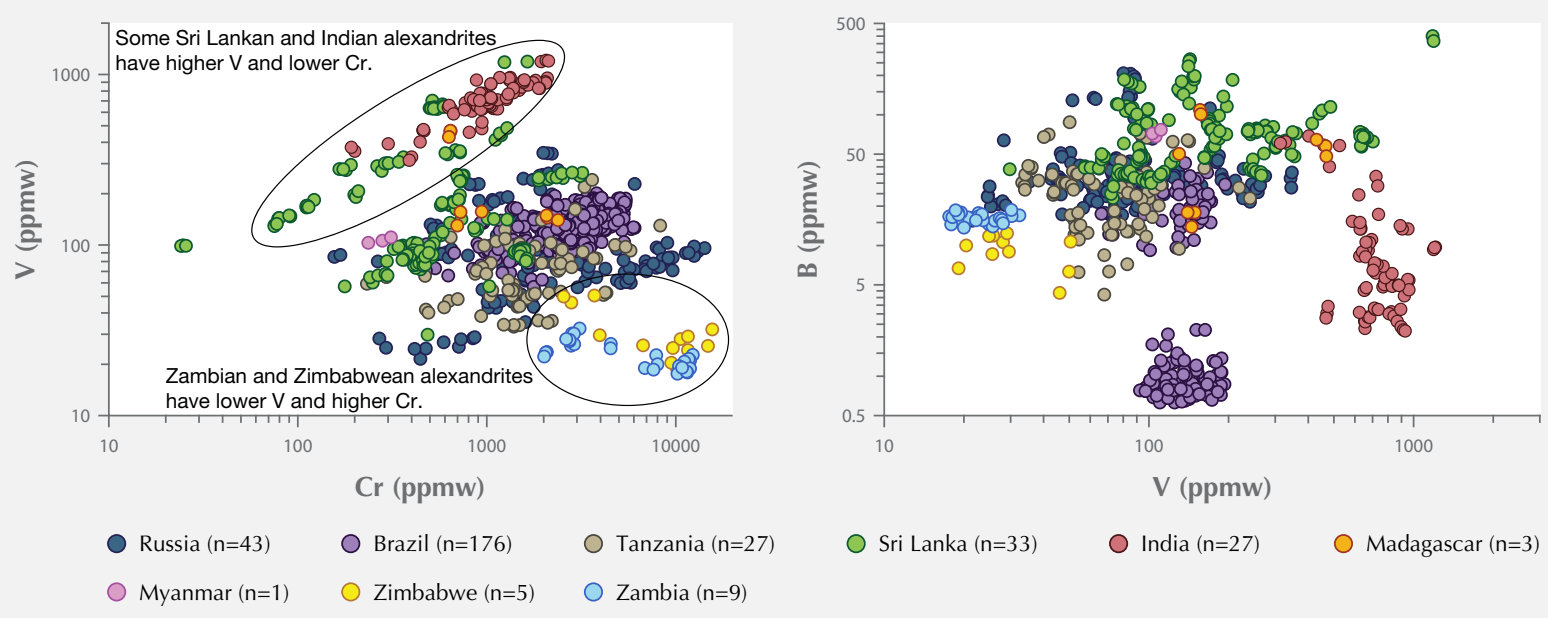

Figure 10. Cr-V and V-B plots prove very useful in validating the origin of Indian, Zambian, and Zimbabwean alexandrites. The Indian stones, along with some of the Sri Lankan specimens, have the highest V/Cr ratios. The Zambian and Zimbabwean stones have the lowest V/Cr ratios.

conclusions (figures 9 and 10). Boron can be used to distinguish Sri Lankan alexandrite from Indian, Zambian, Zimbabwean, and some of the low-boron Brazilian stones (figure 9). According to our reference database, all Sri Lankan alexandrites collected so far have boron concentrations above 20 ppmw, while almost all Indian, Zambian, and Zimbabwean alexandrites have boron concentrations between 2.5 and 20 ppmw, and some Brazilian alexandrites have the lowest boron concentrations, below 2.5 ppmw (figure 9). Besides boron, the chromophores vanadium and chromium are also very important in separating Indian, Zambian, and Zimbabwean alexandrites from material from other localities (figure 10). According to our reference database, some Sri Lankan and all Indian alexandrites have the highest $\mathrm{V} / \mathrm{Cr}$ ratio among all reference stones (indicated by the black oval in the top left of the plot in figure 10). Zambian and Zimbabwean alexandrites have the lowest $\mathrm{V} / \mathrm{Cr}$ ratio among all reference stones (indicated by the black oval in the bottom right of the plot in figure 10).

Selective Plotting for Alexandrite Geographic Origin Determination. We have found that the use of the "selective plotting" method can greatly enhance the accuracy of origin determination for alexandrite (figure 11). The method essentially involves plotting data for the unknown client stone only against reference data with similar full trace element profiles; see Palke et al. (2019), pp. 536-579 of this issue. In this method, discrete "windows" are selectively created around the trace element data of the client stone, and only reference data within these windows are plotted while everything else is filtered out. This results in plots that are much easier to read and accurately interpret. A few examples are shown in figure 11. The plots after discrimination usually point to simple and definite results.

Characteristic Color Change of Alexandrite from Different Countries. Anyone who is familiar with alexandrite is well aware that material from different countries has different characteristic color-change behaviors. Many dealers have a good sense of where a specimen comes from through visual observation under daylight and incandescent lighting conditions. After examining hundreds of alexandrites, we can provide some examples of typical color-change pairings of alexandrite from different countries (figure 12). The images are from stones submitted to GIA at the five different global identification laboratories; each origin was confirmed by analyzing their trace element profiles as measured by LA-ICP-MS. While there is usually a range in the warm/cool color pairs seen for alexandrite from a single locality, each local- 
TABLE 1. Generalized trace element profiles of alexandrite samples in ppmw.

\begin{tabular}{|c|c|c|c|c|c|c|c|c|}
\hline & \multicolumn{8}{|c|}{ Russia } \\
\hline & B & $\mathrm{Mg}$ & V & $\mathrm{Cr}$ & $\mathrm{Fe}$ & $\mathrm{Ga}$ & $\mathrm{Ge}$ & Sn \\
\hline Range & 15.5-208 & $4.47-3140$ & $21.5-347$ & $156-14200$ & 1390-8610 & $171-406$ & $1.08-76.4$ & $37.9-1550$ \\
\hline Average & 45.0 & 93.0 & 102 & 3090 & 2780 & 263 & 10.3 & 324 \\
\hline \multirow[t]{3}{*}{ Median } & 31.4 & 26.1 & 84.0 & 1640 & 2480 & 255 & 4.55 & 244 \\
\hline & \multicolumn{8}{|c|}{ Sri Lanka } \\
\hline & B & $\mathrm{Mg}$ & $\mathrm{V}$ & $\mathrm{Cr}$ & $\mathrm{Fe}$ & $\mathrm{Ga}$ & $\mathrm{Ge}$ & Sn \\
\hline Range & $23.1-400$ & 2.95-987 & $29.8-1190$ & $24.1-3200$ & 1720-12200 & 246-1580 & bdl-2.70 & $7.35-785$ \\
\hline Average & 81.6 & 170 & 211 & 702 & 7680 & 731 & 0.55 & 57.9 \\
\hline \multirow[t]{3}{*}{ Median } & 68.5 & 123 & 146 & 526 & 8090 & 638 & 0.55 & 29.3 \\
\hline & \multicolumn{8}{|c|}{ Brazil } \\
\hline & B & $\mathrm{Mg}$ & $\mathrm{V}$ & $\mathrm{Cr}$ & $\mathrm{Fe}$ & $\mathrm{Ga}$ & $\mathrm{Ge}$ & Sn \\
\hline Range & bdl-42.7 & $2.50-46.7$ & 56.8-201 & $424-6050$ & $4180-11500$ & $53.3-145$ & bdl-2.55 & $87.4-4470$ \\
\hline Average & 2.17 & 11.9 & 136 & 2960 & 6350 & 72.8 & 0.70 & 871 \\
\hline \multirow[t]{3}{*}{ Median } & bdl & 11.1 & 137 & 2870 & 6270 & 69.9 & 0.69 & 821 \\
\hline & \multicolumn{8}{|c|}{ India } \\
\hline & $B$ & $\mathrm{Mg}$ & $\mathrm{V}$ & $\mathrm{Cr}$ & $\mathrm{Fe}$ & $\mathrm{Ga}$ & $\mathrm{Ge}$ & Sn \\
\hline Range & bdl-68.9 & 38.4-203 & 314-1210 & $192-2120$ & $829-4610$ & $168-284$ & bdl-1.68 & $0.28-6.01$ \\
\hline Average & 10.8 & 104 & 722 & 1090 & 2900 & 199 & 0.30 & 1.69 \\
\hline \multirow[t]{3}{*}{ Median } & 5.68 & 102 & 714 & 1020 & 3250 & 195 & 0.28 & 1.33 \\
\hline & \multicolumn{8}{|c|}{ Tanzania } \\
\hline & B & $\mathrm{Mg}$ & $\mathrm{V}$ & $\mathrm{Cr}$ & $\mathrm{Fe}$ & $\mathrm{Ga}$ & $\mathrm{Ge}$ & Sn \\
\hline Range & $4.21-87.8$ & $24.0-270$ & $33.2-241$ & $232-8270$ & 2470-9210 & 54.9-212 & bdl-4.48 & $3.56-192$ \\
\hline Average & 28.3 & 53.3 & 76.1 & 1990 & 5620 & 94.1 & 0.84 & 22.9 \\
\hline \multirow[t]{3}{*}{ Median } & 26.7 & 47.1 & 69.2 & 1500 & 5390 & 85.8 & 0.79 & 14.2 \\
\hline & \multicolumn{8}{|c|}{ Zimbabwe } \\
\hline & B & $\mathrm{Mg}$ & $\mathrm{V}$ & $\mathrm{Cr}$ & $\mathrm{Fe}$ & $\mathrm{Ga}$ & $\mathrm{Ge}$ & Sn \\
\hline Range & bdl-12.4 & $10.9-38.3$ & $19.1-50.6$ & 2550-15600 & 7480-25000 & $269-343$ & bdl-3.19 & $338-2110$ \\
\hline Average & 7.87 & 20.5 & 31.2 & 8700 & 14100 & 313 & 1.78 & 1200 \\
\hline \multirow[t]{3}{*}{ Median } & 8.97 & 19.4 & 28.1 & 9650 & 12700 & 317 & 2.04 & 1080 \\
\hline & \multicolumn{8}{|c|}{ Zambia } \\
\hline & B & $\mathrm{Mg}$ & $\mathrm{V}$ & $\mathrm{Cr}$ & $\mathrm{Fe}$ & Ga & $\mathrm{Ge}$ & Sn \\
\hline Range & $13.7-18.7$ & $10.6-40.9$ & $17.6-32.4$ & 2010-12300 & 9050-13100 & $228-317$ & $1.12-3.8$ & $305-3630$ \\
\hline Average & 16.2 & 21.5 & 23.2 & 6720 & 11000 & 276 & 2.19 & 1270 \\
\hline \multirow[t]{3}{*}{ Median } & 16.3 & 18.0 & 22.6 & 6860 & 10900 & 277 & 2.04 & 668 \\
\hline & \multicolumn{8}{|c|}{ Madagascar } \\
\hline & B & $\mathrm{Mg}$ & $\mathrm{V}$ & $\mathrm{Cr}$ & $\mathrm{Fe}$ & Ga & $\mathrm{Ge}$ & Sn \\
\hline Range & 13.9-109 & $56.2-136$ & $130-468$ & $630-2380$ & $4770-7840$ & $106-338$ & bdl-0.69 & $4.16-205$ \\
\hline Average & 53.4 & 97.4 & 249 & 1200 & 6850 & 248 & 0.077 & 57.7 \\
\hline \multirow[t]{3}{*}{ Median } & 50.3 & 97.2 & 156 & 726 & 7280 & 289 & bdl & 12.7 \\
\hline & \multicolumn{8}{|c|}{ Myanmar } \\
\hline & B & $\mathrm{Mg}$ & $\mathrm{V}$ & $\mathrm{Cr}$ & $\mathrm{Fe}$ & $\mathrm{Ga}$ & $\mathrm{Ge}$ & Sn \\
\hline Range & $68.3-76.8$ & $495-531$ & $103-111$ & $236-311$ & $1270-1530$ & $114-129$ & bdl-bdl & $1100-1640$ \\
\hline Average & 72.3 & 519 & 107 & 276 & 1360 & 120 & bdl & 1440 \\
\hline \multirow[t]{3}{*}{ Median } & 71.9 & 530 & 106 & 280 & 1290 & 118 & bdl & 1580 \\
\hline & \multicolumn{8}{|c|}{ Detection limits (ppmw) } \\
\hline & B & $\mathrm{Mg}$ & $\mathrm{V}$ & $\mathrm{Cr}$ & $\mathrm{Fe}$ & $\mathrm{Ga}$ & $\mathrm{Ge}$ & Sn \\
\hline Range & $0.091-0.15$ & $0.014-0.034$ & $0.008-0.021$ & $0.15-0.26$ & $0.87-1.63$ & $0.007-0.031$ & $0.037-0.11$ & $0.026-0.065$ \\
\hline
\end{tabular}




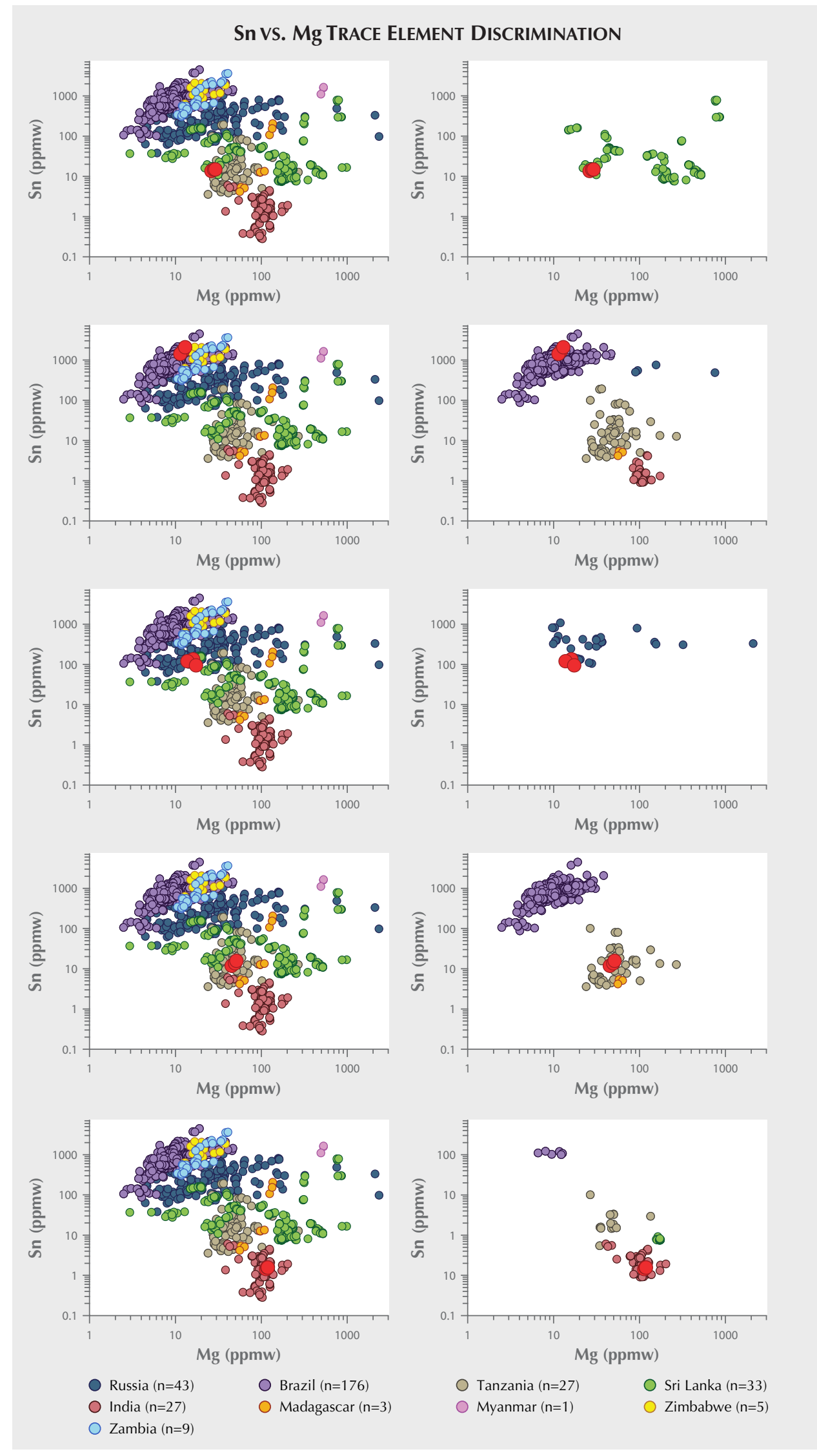

Figure 11. The left column shows Sn-Mg plots before discrimination for alexandrite from (top to bottom) Sri Lanka, Brazil, Russia, Tanzania, and India. The right column shows the same Sn-Mg plots after application of the selective plotting method. This method leaves in reference data that are similar to unknown stones and filters out irrelevant information, making these plots much easier to interpret accurately. 
ity does tend to have its own specific range, and the different colors seen are generally helpful in narrowing down the origin. The color types for each country in figure 12 were determined based on both colorimetric analyses of the images and visual observations by gemologists.

Sri Lankan alexandrites usually have a yellowish green component in daylight-equivalent lighting and a brownish or orangy component with incandescent illumination. Brazilian alexandrites tend to have a bluish green component in daylight-equivalent lighting and a reddish purple to purple component under incandescent light. The color-change characteristics of alexandrites from other countries are not as well known, because of the limits of our current image database.

Geographic origin determinations should never be based on color alone; trace element chemistry is the primary factor in establishing origin. However, color can support the origin determination derived from trace element chemistry. The authors grouped all types of alexandrite color-change pairings into the following general categories (corresponding to types in figure 12):

\section{Sri Lanka - Cool}

Even though Sri Lankan alexandrites typically have brownish to grayish overtones, some lack these overtones and fall into the Cool category. In lighter-toned stones, hue changes from green or bluish green in daylight to purplish red or grayish purple in incandescent light. Saturation is low to medium in fine-quality stones, with a medium to dark tone.

\section{Sri Lanka - Warm}

Specimens in the Warm category exhibit the typical brownish to grayish overtones that characterize many Sri Lankan alexandrites. Daylight hues are generally yellowish compared to other alexandrites, ranging from yellowish green to brownish yellow to the occasional pure green. In incandescent light, they usually appear brownish, with yellowish brown, orangy brown, brownish pink, brownish purple, brownish yellow, and brownish red hues. Saturation is generally low to medium, with medium to dark tones.

\section{Brazil}

Top Brazilian stones are generally considered to exhibit the finest color change of any alexandrites. Most tend to have a bluish component to their daylight color. Their hues are greenish blue to blue-green to pure green in daylight and red-purple to purple in incandescent light. These colors are often vivid, with medium to high saturation and medium to dark tone.

\section{Russia}

Russian alexandrite can exhibit some of the finest colors in top-quality material. Hues are generally pure green to bluish green to greenblue in daylight and purple-red to purple in incandescent light. Stones tend to have medium to high saturation, with medium to dark tone.

\section{Tanzania}

Tanzanian alexandrite is capable of producing superb color change. Hue tends to range from bluish green to greenish blue in daylight and red-purple to purple in incandescent light. Tanzanian stones typically have medium to high saturation and medium to dark tone.

\section{India}

Hue for Indian alexandrite tends to range from green to bluish green in daylight, changing to purplish violet, purple, brownish purple, or redpurple in incandescent light. Indian stones typically have low to medium saturation and medium to dark tone.

Inclusions in Alexandrite from Different Countries. Geological environment not only controls the presence of certain trace elements and their concentration but also impacts the inclusions an alexandrite contains. GIA has captured photomicrographs of inclusions in alexandrite and is using them to support the origin determinations made by chemistry and color.

Brazil. Metal sulfides have frequently been found in Brazilian alexandrites (figure 13A and B) and are almost diagnostic for this origin in the authors' opinion, although alabandite, a metal sulfide with similar appearance to the inclusions in figure $13 \mathrm{~A}$ and $\mathrm{B}$, was reported by Gübelin and Koivula (1986) in a noncolor-change Sri Lankan chrysoberyl. Minute particles sometimes group together to form fingerprints (figure 13C) and wispy clouds (figure 13D). Crystals of fluorite (figure 13E) and mica crystals and flakes (possibly phlogopite or biotite, figure 13F) are also observed occasionally. Other researchers have also reported fluorite, phlogopite, and biotite and 


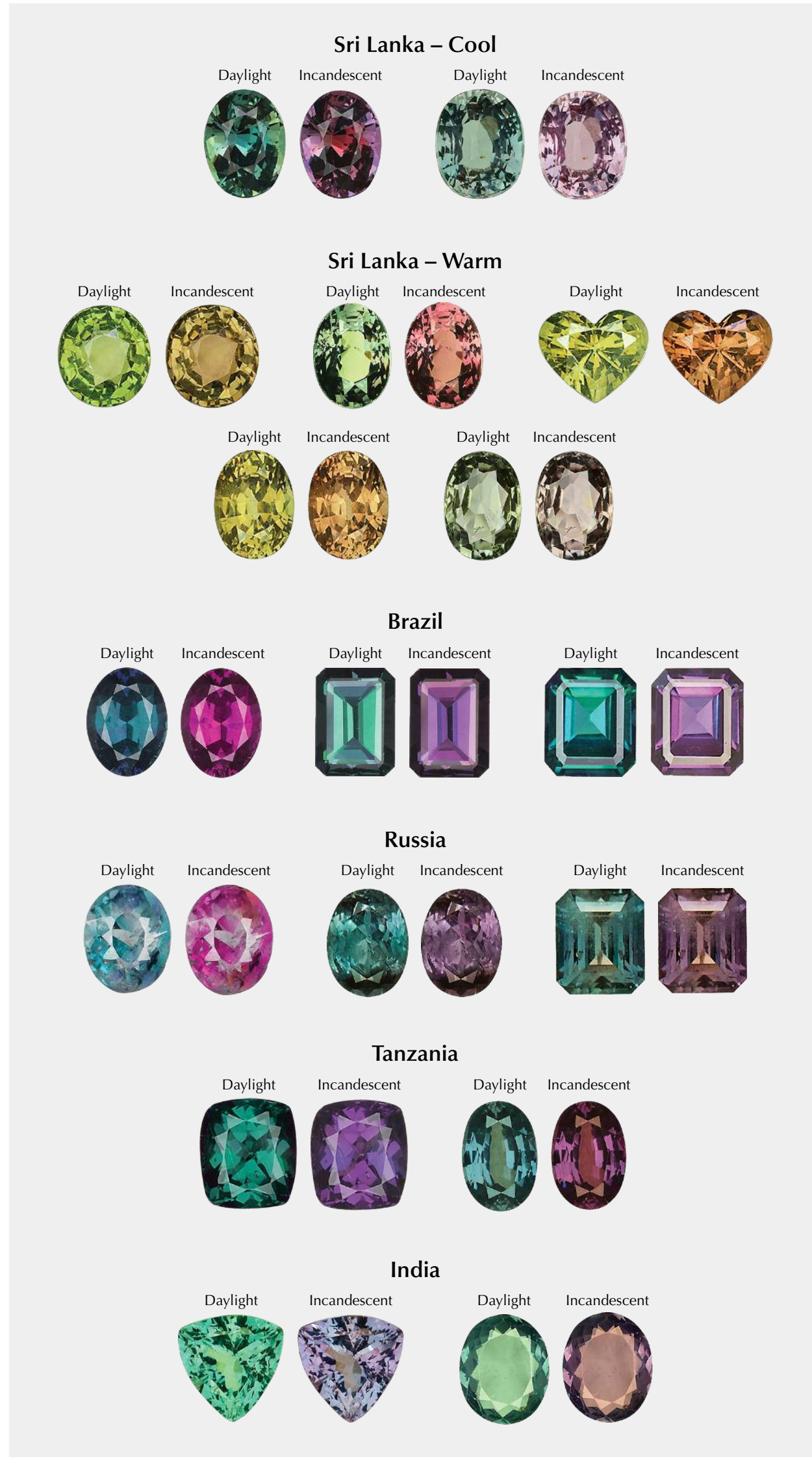

Figure 12. Characteristic color-change pairings of alexandrite from different countries. The photos were selected from GIA's digital imaging database of production stones, which were taken using GIA digital imaging procedures and printed on GIA alexandrite reports. 

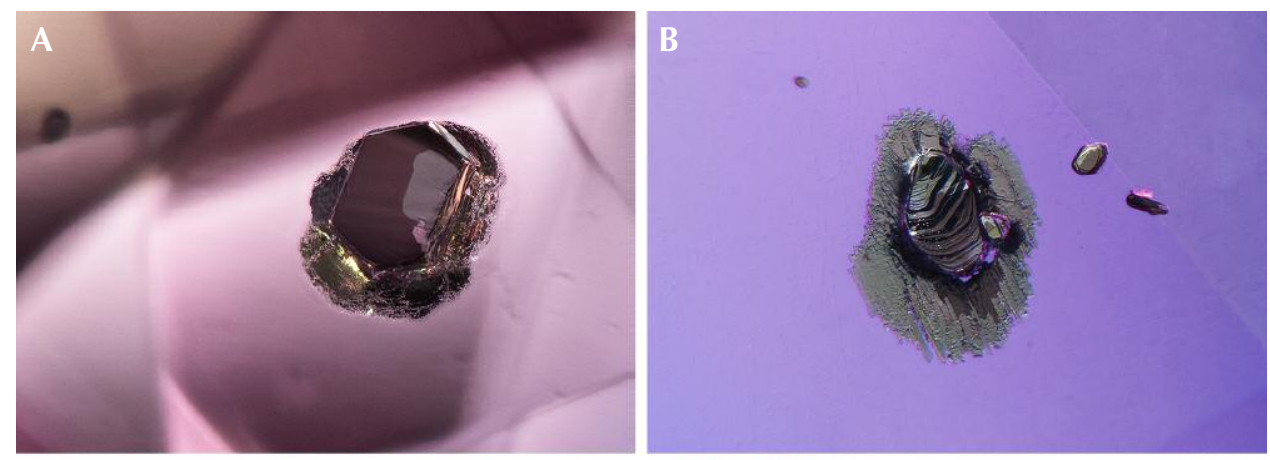

Figure 13. Inclusions in Brazilian alexandrite. A: A metal sulfide crystal inclusion surrounded by $a$ melted/decrepitated halo under diffused fiber-optic illumination. B: Chalcopyrite crystal surrounded by melted/decrepitated halo under darkfield and
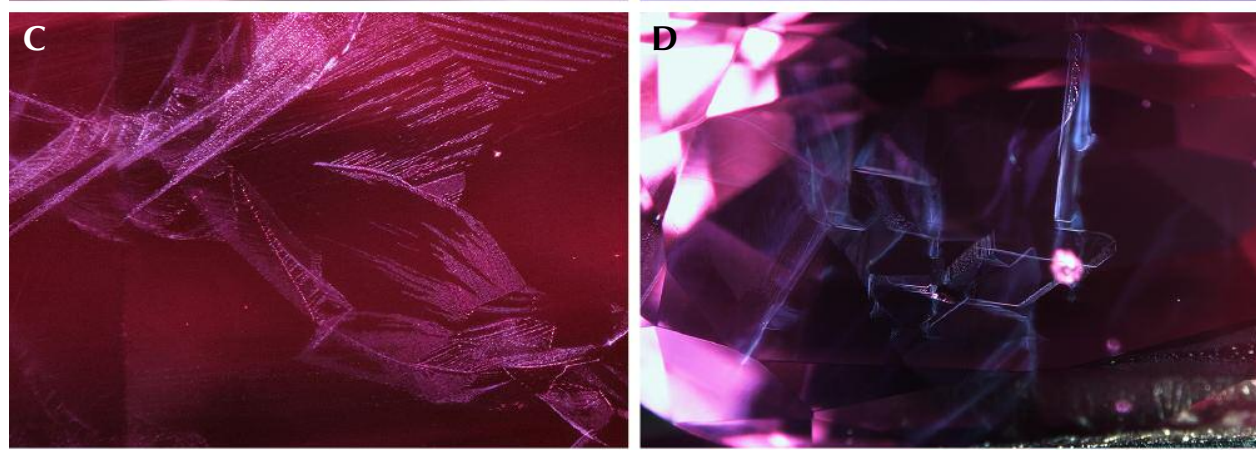

oblique fiber-optic illumination. C: Silk, bands, and fingerprints composed of minute particles under oblique fiber-optic illumination. D: Clouds/fingerprints composed of minute particles under darkfield and oblique fiber-optic illumination. E: Rounded fluorite crystal inclusions under diffused illumination. F:
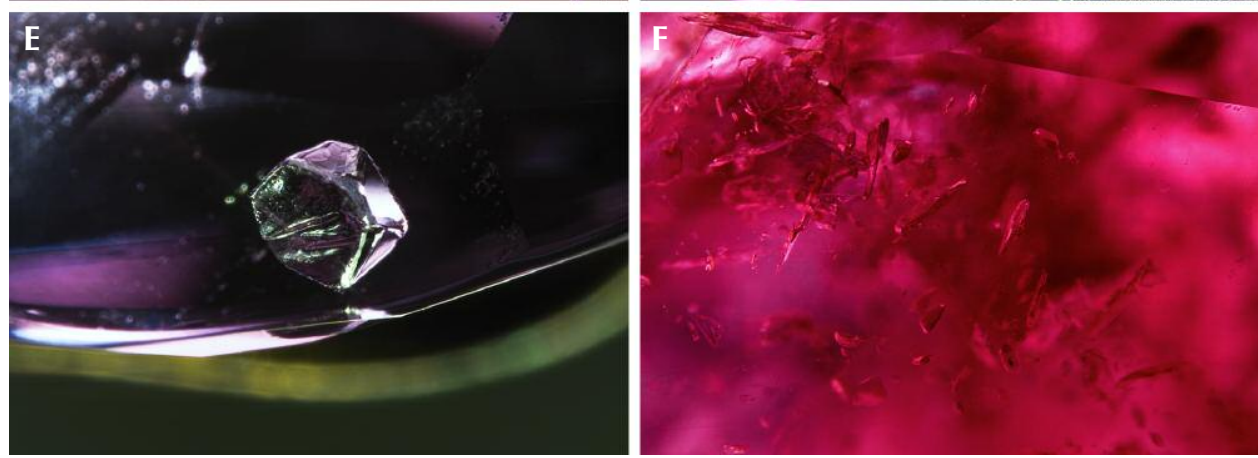
Mica crystals under darkfield illumination. Fields of view: $1.99 \mathrm{~mm}(\mathrm{~A}), 1.42$ $\mathrm{mm}(B), 2.34 \mathrm{~mm}(C), 7.19$ $\mathrm{mm}(D), 0.55 \mathrm{~mm}(E)$, and $2.00 \mathrm{~mm}(\mathrm{~F})$. Photomicrographs by Jonathan Muyal $(A, C)$, Tyler Smith $(B, D$, $E)$, and Makoto Miura (F).

additionally calcite, apatite, albite, and two-phase and multiphase fluid inclusions in Brazilian alexandrites (Gübelin and Koivula, 1986; Proctor, 1988; Koivula and Kammerling, 1988).

Sri Lanka. Sri Lankan stones submitted to GIA are usually clean, but the identification team has still documented many inclusions. Strong brown color zoning has only been observed in Sri Lankan stones and may be diagnostic of this origin (figure 14A), although additional observations are needed to confirm this. Under fiber-optic illumination, these brown color zones are populated with reflective milky clouds (figure 14B). Very rarely, elongate prismatic sillimanite crystals (figure 14C) and euhedral feldspar crystals (figure 14D) have been observed. Fingerprints (figure 14E and F) formed by two-phase and multiphase fluid inclusions are normal. Minute particles may group together to form flake-like clouds (figure 14G). Occasionally, tubes with brownish oxide stains (figure $14 \mathrm{H}$ ) can also be observed. Additionally, green mica, quartz crystals, and slender rod-like crystals of columbite, spessartine, ilmenite, and alabandite have previously been observed in Sri Lankan alexandrites and non-color-change chrysoberyls (Gübelin and Koivula, 1986).

Russia. In our limited observations of inclusions in Russian alexandrite, phlogopite mica has been seen forming flattened, rounded, unevenly shaped crystals (figure 15A) and clusters of cotton-like inclusions (figure 15B). Very rarely, corroded and rounded fluorite crystals (figure 15C) and prismatic rod-like tourmaline crystals (figure 15D) have been observed. Both inclusions were first reported in Russian alexandrites. Tourmaline crystals, chemically identified as 

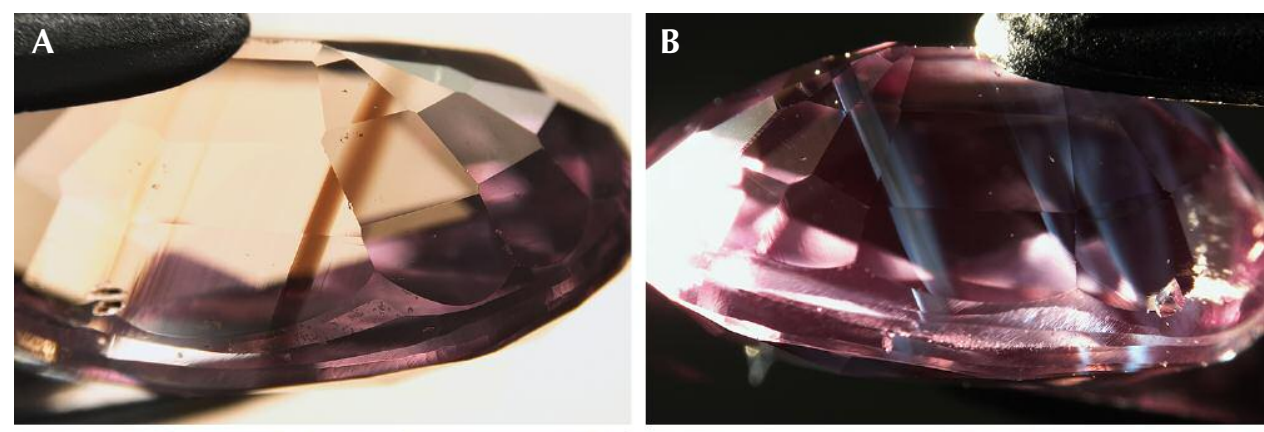

Figure 14. Inclusions in Sri Lankan alexandrite. A: Brown color zoning and strong parallel graining under brightfield illumination. B: The same brown color zoning in $(A)$ becomes milky bands under darkfield and
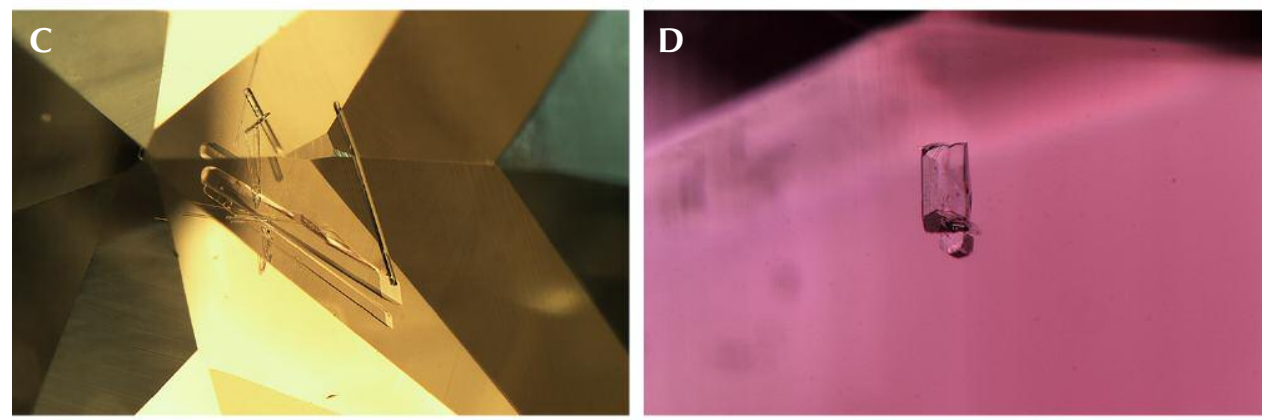

oblique fiber-optic illumination. C: Well-formed prismatic sillimanite crystals under darkfield and oblique fiber-optic illumination. D: Euhedral feldspar crystal under diffused illumination. E: Fingerprints formed by parallel lines of fluids and tiny crystals under darkfield and diffused
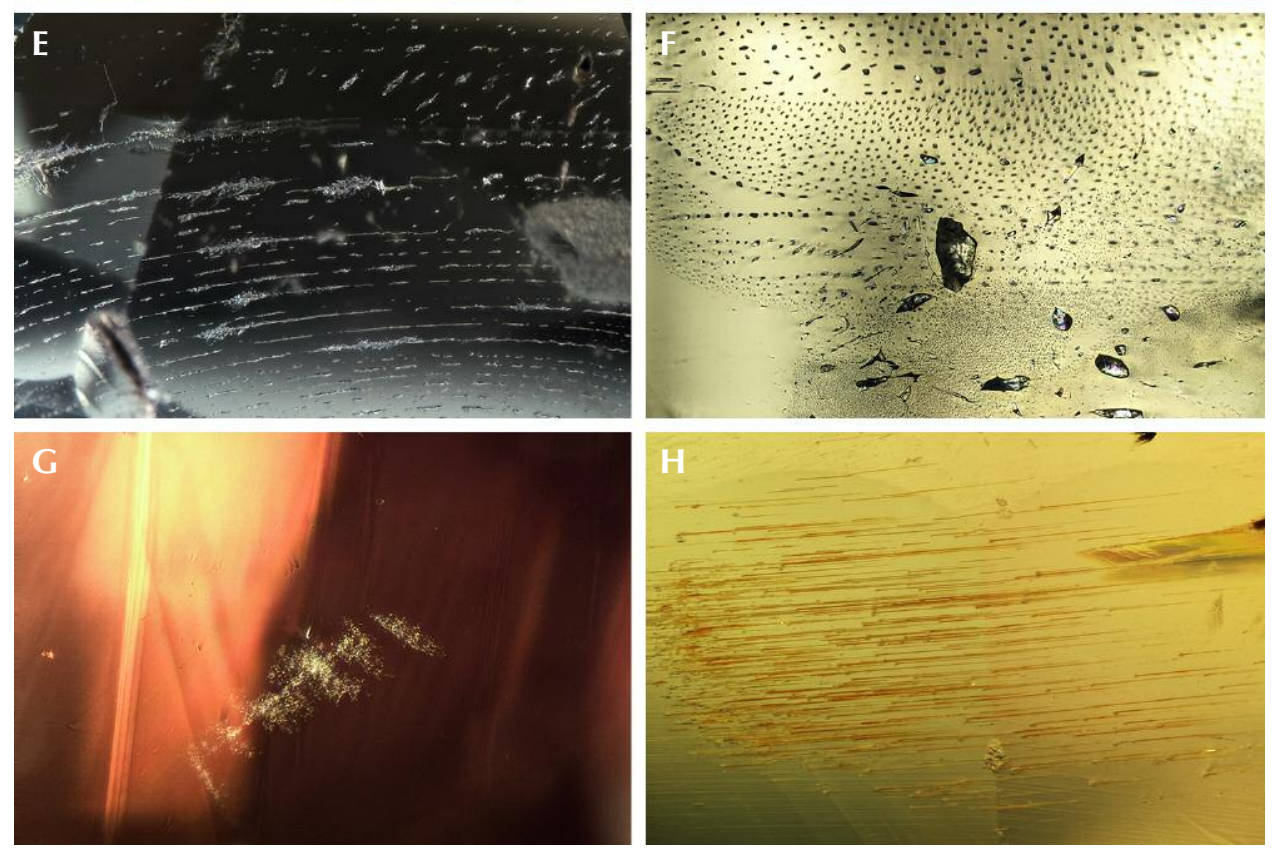

fiber-optic illumination. F: Irregularly shaped crystals and fingerprints composed of two-phase and multiphase fluid inclusions under darkfield illumination. G: Flake-like cloud of particles under oblique fiber-optic illumination. H: Tubes with brownish oxide stains under diffused fiber-optic illumination. Fields of view: $7.19 \mathrm{~mm}(A), 7.19$ $\mathrm{mm}(B), 2.90 \mathrm{~mm}(C)$, $1.99 \mathrm{~mm}(D), 2.90 \mathrm{~mm}$ (E), $3.57 \mathrm{~mm}(F), 1.44 \mathrm{~mm}$ $(G)$, and $1.99 \mathrm{~mm}(H)$. Photomicrographs by Tyler Smith $(A-D)$ and Jonathan Muyal (E-H).

dravite by LA-ICP-MS (Sun et al., 2019), may be diagnostic of the origin, although additional observations are needed to confirm this. Sometimes it is not difficult to see pseudo-hexagonal growth sections shown in different colors under brightfield illumination between crossed polarizers (figure 15E). Graphite film, resembling a spaceship in figure 15F, has been occasionally observed in Russian material. Rounded cotton-like clouds composed of tiny particles (figure 15G) show unique texture and may be diagnostic.
Planes of fluid inclusions (figure 15H) have also been observed. Further work is underway to collect additional information on reliably sourced Russian alexandrite. Mica (e.g., phlogopite and biotite) and amphibole inclusions are most commonly observed in Russian alexandrites (Gübelin and Koivula, 1986).

Tanzania. For alexandrite from Tanzania, inclusions of actinolite crystals, mica, monazite, xenotime, and rounded metamict zircon have been observed (Gübe- 

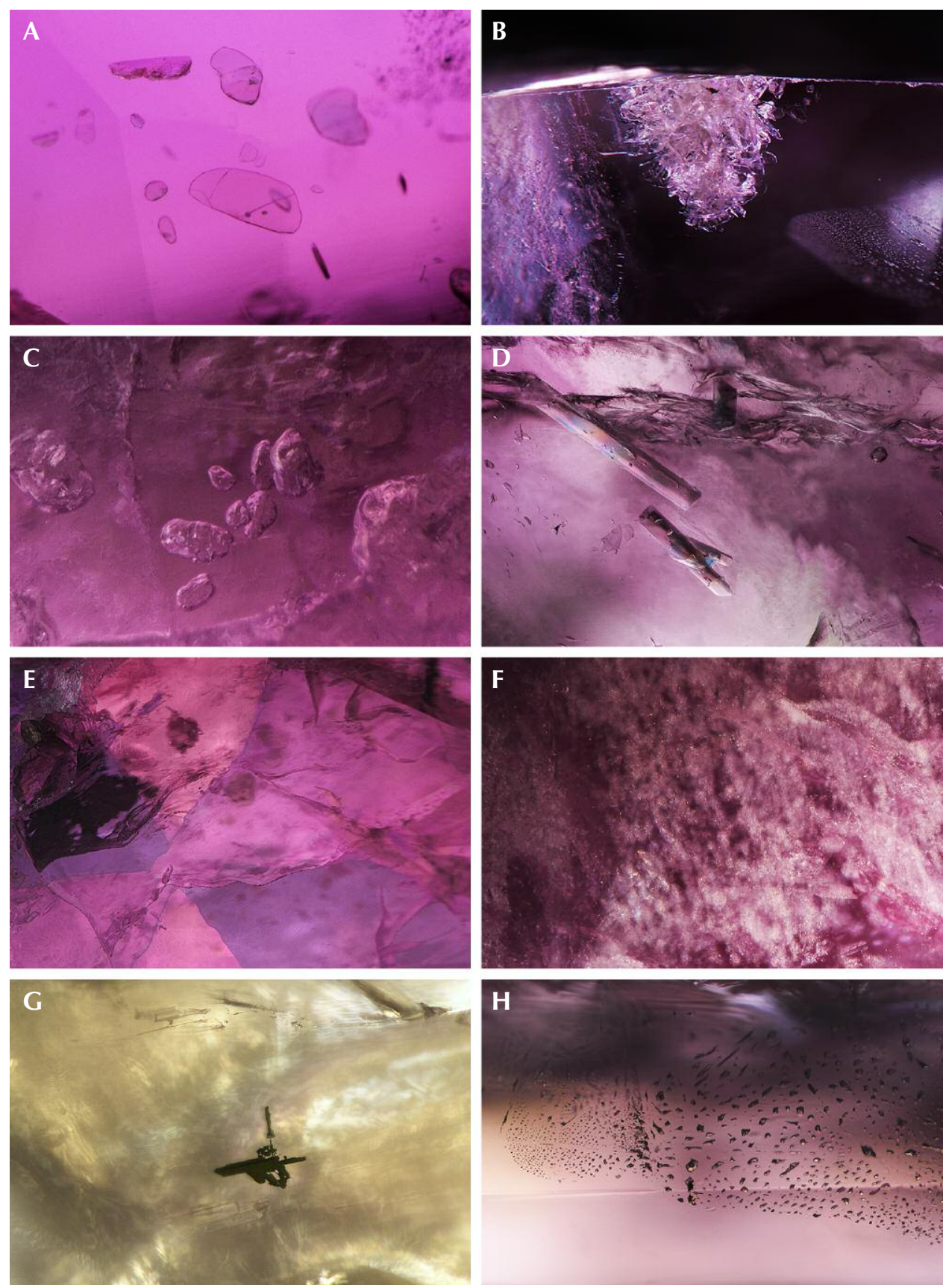

Figure 15. Inclusions in

Russian alexandrite. A:

Rounded, unevenly

shaped flat transparent

phlogopite crystals under

darkfield illumination.

$B$ : A dense cluster of col-

orless, bladed phlogopite

crystals breaks the sur-

face of the stone under

darkfield and oblique

fiber-optic illumination.

C: Corroded and rounded

fluorite crystals under

diffused illumination.

D: Prismatic rod-like

tourmaline crystals

under brightfield illumi-

nation between crossed

polarizers. E: Pseudo-

hexagonal growth sec-

tions shown in different

colors under brightfield

illumination between

crossed polarizers. F:

Graphite film under

darkfield illumination.

G: Rounded cotton-like

clouds under oblique

fiber-optic illumination.

$H$ : Minute two-phase and multiphase fluid finger

prints under diffused illumination. Fields of view: $0.80 \mathrm{~mm}(A), 1.99 \mathrm{~mm}$ (B), $1.26 \mathrm{~mm}(C), 1.44$ $\mathrm{mm}(D), 3.57 \mathrm{~mm}(E)$, $0.72 \mathrm{~mm}(F), 4.79 \mathrm{~mm}$ $(G)$, and $1.44 \mathrm{~mm}(\mathrm{H})$. Photomicrographs by Makoto Miura (A), Tyler Smith (B), and Jonathan Muyal (C-H).

lin and Koivula, 1986). Currently, there are only a few images of crystals and fingerprint-like inclusions in GIA's production database. Groups of prismatic apatite crystals (figure 16A, B, and C) and nests of fine silk (figure 16D) have been observed in one Tanzanian alexandrite.

India. Fingerprint-like inclusions in Indian alexandrite are usually composed of tiny needles and oval and round reflective particles (figure 17A, B, and C).
This feature may be diagnostic of the origin, although additional observations are needed to confirm this. Occasionally, zircon crystals (figure 17D) with tension fissures have been observed. Figure 17E shows two adjacent crystals with unknown identity; the larger one shows a metallic luster. Groups of elongate negative crystals (figure 17F) are also observed sometimes in Indian alexandrite. Additionally, mica flakes (biotite, muscovite, etc.) are often observed (Panjikar and Ramchandran, 1997). Quartz 

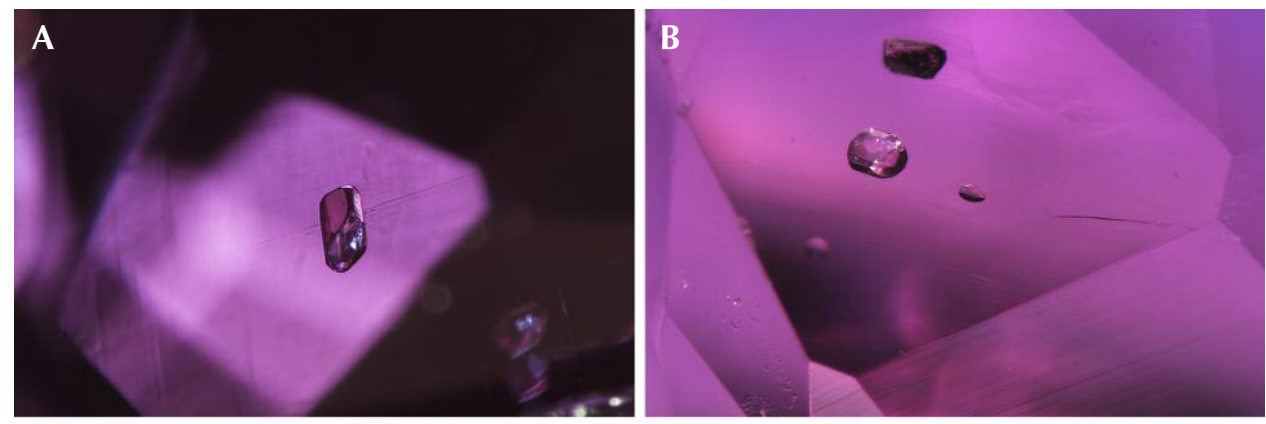

Figure 16. Inclusions in

Tanzanian alexandrite. A:

Prismatic apatite crystal

with slightly rounded edges and uneven termination. B: Large colorless apatite crystal on the left and smaller, slightly tapered phlogopite crystal on the right. C: Apatite crystal with faint nee-
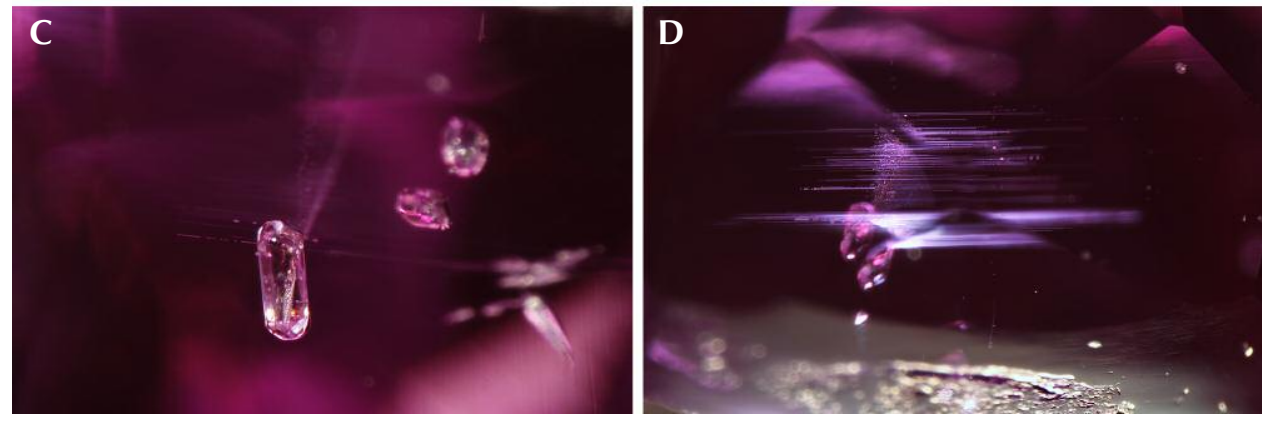
dles and particles. D: Nest of fine silk and small platelets. The " $X$ " is an artifact from the facet junctions. Fields of view: 1.99 $\mathrm{mm}(\mathrm{A}), 1.76 \mathrm{~mm}(B), 1.76$ $\mathrm{mm}(C)$, and $2.90 \mathrm{~mm}(D)$. Photomicrographs by Tyler Smith; oblique fiber-optic and darkfield illumination.

and apatite crystals (Patnaik and Nayak, 1993) are sometimes randomly scattered or in isolation. Needles of rutile and colorless sillimanite can also be observed (Panjikar and Ramchandran, 1997).

Other Localities. GIA lacks inclusion information on alexandrite from Madagascar, Zimbabwe, Zambia, and Myanmar. The field gemology team is actively working to expand GIA's reference collection for these stones.

\section{CONCLUSIONS}

Determining alexandrite's geographic origin is a complicated process that requires careful examination of a wide range of physical and chemical properties. In order to make a final determination, we evaluate a combination of the three most important characteristics: trace element chemistry, color-change behavior under daylight-equivalent lighting and incandescent illumination, and inclusions. Of these three characteristics, trace element chemistry obtained from LAICP-MS is the primary consideration. Color and inclusions are used as secondary factors to support the origin determination derived from trace element chemistry.

The trace elements $\mathrm{Mg}, \mathrm{Fe}, \mathrm{Ga}, \mathrm{Ge}$, and $\mathrm{Sn}$ are the five best discriminators to distinguish alexandrite from the major producing countries of Russia (figure 18), Sri Lanka, Brazil, India, and Tanzania. B, V, and $\mathrm{Cr}$ are good discriminators for separating alexandrites among some countries, but they must be considered as a complement to the first five trace elements with specific criteria, rather than on their own.

Most Sri Lankan alexandrites have a yellowish green component in daylight-equivalent lighting and a brownish or orangy component in incandescent illumination. Brazilian alexandrites have a bluish green component in daylight-equivalent lighting and a purple to purplish red component in incandescent illumination. The color characteristics of alexandrites from other sources are less well known at the moment, but this remains an area of active research.

Sulfides with metallic luster may be diagnostic inclusions for Brazilian alexandrites. Prismatic rodlike tourmaline crystals and rounded cotton-like clouds composed of tiny particles may be diagnostic for Russian alexandrites. Fingerprint-like inclusions composed of tiny needles and oval and round reflective particles may be unique to Indian alexandrites. Strong brown color zoning is a good indication of Sri Lankan origin. Characterization of inclusion scenes in alexandrite from the various localities is an active area of research in this project, and future work may help identify additional microscopic indicators of a stone's origin.

Alexandrite origin is an ongoing project for the GIA research and identification department. One of the largest efforts on this front is to add samples obtained by GIA's field gemology team to our reference database. It can be difficult to find reliable alexandrite samples from secondary deposits such as Sri Lanka, 

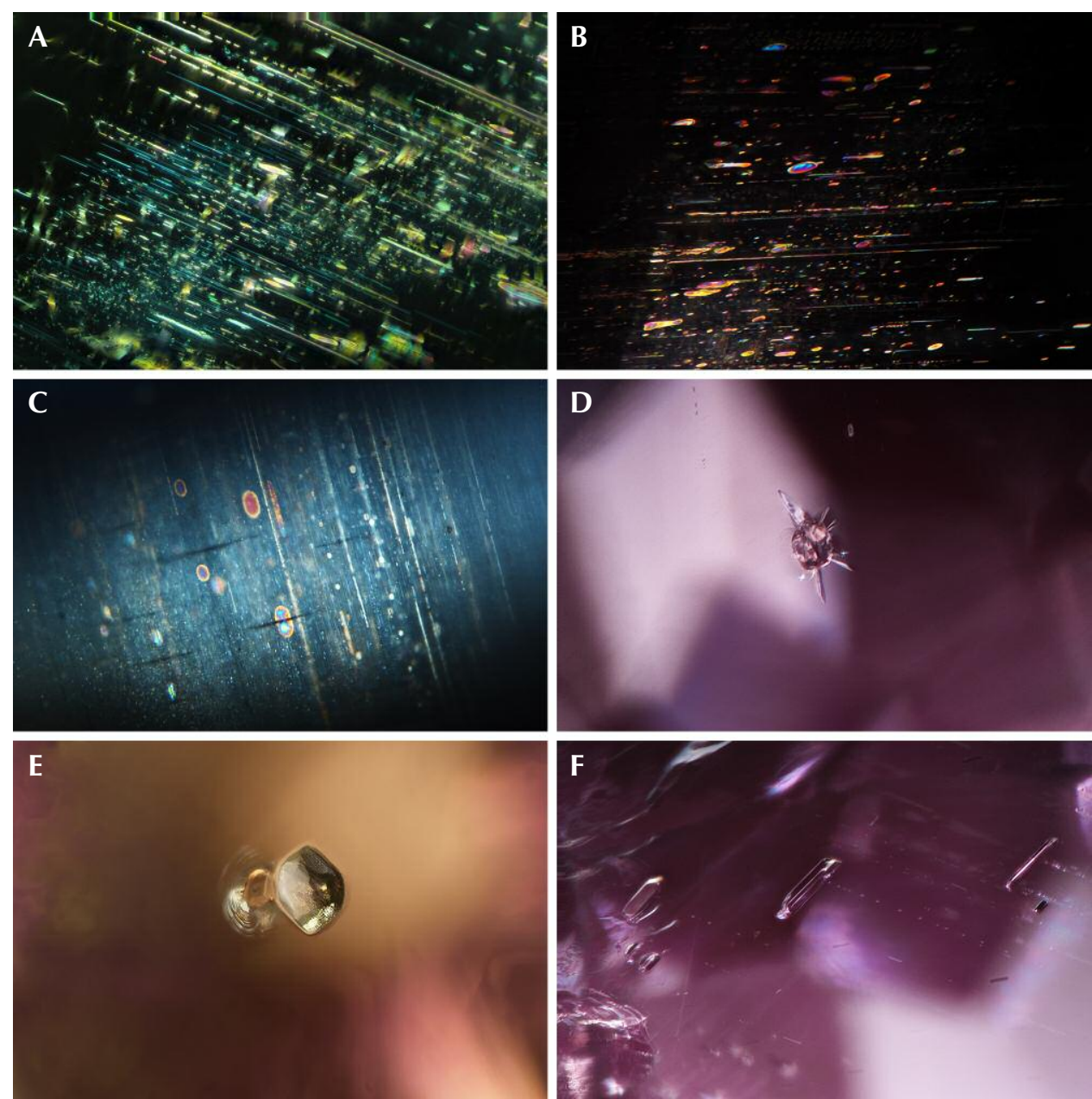

Figure 17. Inclusions in Indian alexandrite. A: Needles and tiny ovalshaped reflective particles under oblique fiber-optic and darkfield illumination. B: Needles and tiny oval reflective particles under darkfield illumination. C: Needles, a minute and large reflective oval, and round particles under darkfield illumination. $D$ : Zircon crystal inclusion surrounded by tension fissures under darkfield illumination. E: Large unknown crystal with metallic luster and adjacent small crystal with halo-like tension fissure under darkfield illumination. F: Elongate negative crystals under diffused illumination. Fields of view: $0.72 \mathrm{~mm}(\mathrm{~A}), 1.26$ $\mathrm{mm}(B), 2.41 \mathrm{~mm}(C), 1.26$ $\mathrm{mm}(D), 1.44 \mathrm{~mm}(E)$, and $1.58 \mathrm{~mm}(F)$. Photomicrographs by Jonathan Muyal $(A, B, D, E, F)$ and Makoto Miura (C).

Tunduru in Tanzania, or Ilakaka in Madagascar. That is why our reference data were obtained from trusted members of the trade or the GIA Museum. As this new origin service evolves, future efforts of the field gemology team will focus on obtaining samples from these sources as material becomes available. Addi-

Figure 18. Russian alexandrite in daylight-equivalent light (left) and incandescent light (right). The twinned crystal from Malysheva measures $32.35 \mathrm{~mm}$, and the faceted stone weighs $2.61 \mathrm{ct}$. Photos by Robert Weldon/GIA; courtesy of William Larson.
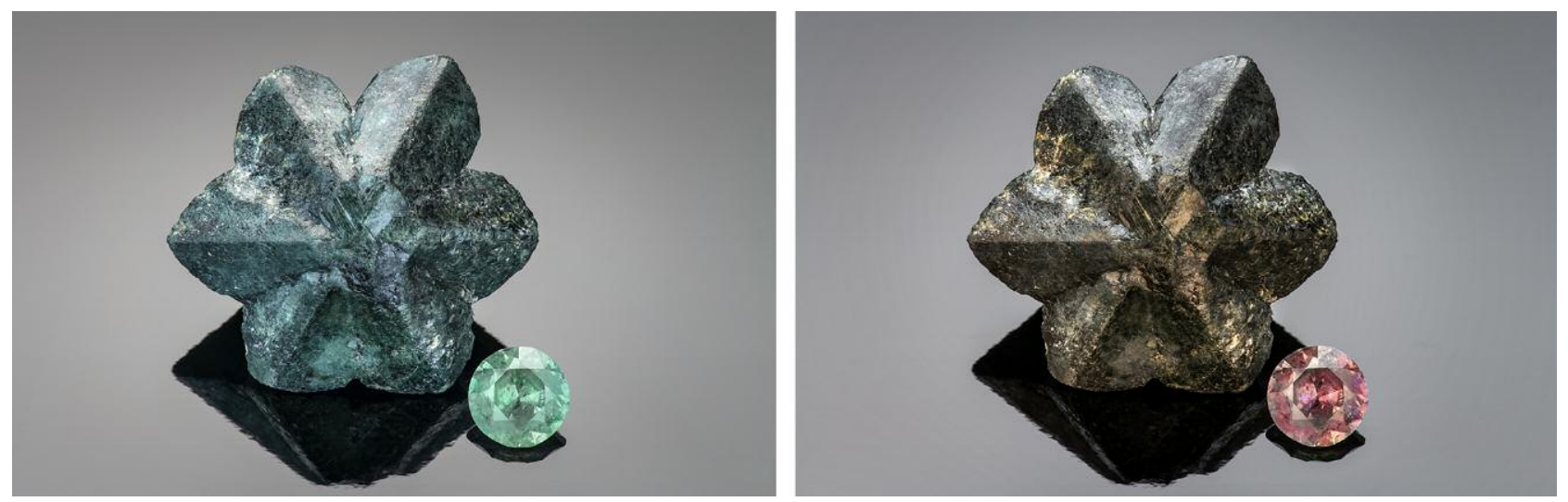
tionally, the internal crystal growth pattern and morphology of rough crystals have been used as factors for geographic origin determination by other researchers (Schmetzer, 2011; Schmetzer and Malsy, $2011 \mathrm{a}, \mathrm{b})$. These two areas can enhance our current methods and are worth investigating. Third, different deposits within a country can contain crystals with very different morphologies, producing material with varying trace element chemistries that show different colors and inclusions. Further work will be needed to collect additional data on stones from all major locations in order to delineate the differences, not only for alexandrite from different geographic locations but also for alexandrite from a single source. In this there is a truth that applies to all gemological laboratories, no matter how mature and well established: We must remain vigilant and continue expanding the state of our gemological knowledge if we are to uncover the story of any precious stone that passes through our hands.

\section{ABOUT THE AUTHORS}

Mr. Sun is a research associate, Dr. Palke is a senior research scientist, Mr. Muyal is a former staff gemologist, Mr. DeGhionno is senior manager of colored stone services, and Mr. McClure is global director of colored stone services at GIA's laboratory in Carlsbad, California.

\section{ACKNOWLEDGMENTS}

The authors deeply thank Omi Privé for providing high-end alexandrite jewelry and faceted stones for photography. Evan Caplan, John Koivula, and LC Gem Collection Inc. are greatly thanked for providing high-end faceted alexandrite and rough mineral specimens for photography. Warren Boyd, Evan Caplan, Vincent Pardieu, Chandika Thambugala, Nilam Alawdeen, Yusuke
Katsurada, Lance Davidson (Davidson Inc.), LC Gems Collection Inc., and Spectrum Fine Jewelry \& Exotic Gems are thanked for providing alexandrite stones for chemical analysis and taking photomicrographs of inclusions to build our reference database. We are deeply grateful to Robert Weldon and Kevin Schumacher for their alexandrite photos. Robison McMurtry and Diego Sanchez provided GIA's digital imaging procedures for color-change stones. Many thanks are owed to Yusuke Katsurada, Makoto Miura, Sudarat Saeseaw, Vararut Weeramonkhonlert, Daniel Girma, Tyler Smith, Virginia Schneider, Mei Mei Sit, Sze Ling Wong, Chun Fai Chow, Nathan D. Renfro, Claire Malaquias, and Christopher M. Breeding for constant support and contributions on sample testing and data collection and the important suggestions they provided throughout the project.

\section{REFERENCES}

Alexandrite world occurrences \& mining localities (n.d.) Alexandrite Tsarstone Collectors Guide, https://www.alexandrite.net/ localities/index.html

Bevan A.W.R., Downes P.J. (1997) Alexandrite chrysoberyl from Dowerin, Western Australia: Revisited. Australian Gemmologist, Vol. 19, No. 11, pp. 460-463.

Brown G., Kelly S.M.B. (1984) Alexandrite-chrysoberyl from Zimbabwe. Australian Gemmologist, Vol. 15, No. 8, pp. 275-278.

Brunel F. (1972) Jewellery of India: Five Thousand Years of Tradition. National Book Trust, New Delhi, 82 pp.

Cassedanne J., Roditi M. (1993) The location, geology, mineralogy and gem deposits of alexandrite, cat's-eye and chrysoberyl in Brazil. Journal of Gemmology, Vol. 23, No. 6, pp. 333-354.

Costanza F. (1998) Supplies of alexandrite are scarcer than ever. National Jeweler, Vol. 42, No. 5, pp. 16-18.

Downes P.J., Bevan A.W.R. (2002) Chrysoberyl, beryl and zincian spinel mineralization in granulite-facies Archaean rocks at Dowerin, Western Australia. Mineralogical Magazine, Vol. 66, No. 6, pp. 985-1002, http://dx.doi.org/10.1180/0026461026660072

Groat L.A., Giuliani G., Stone-Sundberg J., Renfro N.D., Sun Z. (2019) A review of analytical methods used in geographic origin determination of gemstones. Gせ G, Vol. 55, No. 4, pp. 512-535, http://dx.doi.org/10.5741/GEMS.55.4.512

Gübelin E.J. (1976) Alexandrite from Lake Manyara, Tanzania. $G \uplus G$, Vol. 15, No. 7, pp. 203-209.
Gübelin E.J., Koivula J.I. (1986) Photoatlas of Inclusions in Gemstones, Vol. 2. Opinio Publishers, Basel, Switzerland, 829 pp.

Hänni H.A. (1999) .... And other gems from near Ilakaka. $G \uplus G$, Vol. 35, No. 2, p. 150.

Henricus J. (2001) New gem rush in Tanzania. Jewellery News Asia, No. 197, pp. 78-80.

Jarrett D. (2015) The story behind the stone: Another source, another phenomenon. Mid-America Jewelry News, Nov. 1, p. 22, https://midamericajewelrynews.com/columnists/dianajarrett/3135-the-story-behind-the-stone-another-sourceanother-phenomenon

Jochum K.P., Nohl U., Herwig K., Lammel E., Stoll B., Hofmann A.W. (2005) GeoReM: A new geochemical database for reference materials and isotopic standards. Geostandards and Geoanalytical Research, Vol. 29, No. 3, pp. 333-338, http://dx.doi.org/ 10.1111/j.1751-908X.2005.tb00904.x

Johnson M.L., Koivula J.I. (1996) Gem News: Gem materials from the new locality at Tunduru, Tanzania. Ge G, Vol. 32, No. 1, pp. 58-59.

(1997) Gem News: Tunduru-Songea gem fields in southern Tanzania. GÆ G, Vol. 33, No. 4, p. 305.

Koivula J.I. (1987a) Gem News: Brazilian alexandrites. $G \uplus G$, Vol. 23, No. 2, p. 123.

(1987b) Gem News: More on Brazilian alexandrites. $G \nrightarrow G$, Vol. 23, No. 4, pp. 238-240. 
Koivula J.I., Kammerling R.C. (1988) Gem News: Inclusions identified in new Brazilian alexandrites. $G \uplus G$, Vol. 24, No. 1, p. 59.

Kozlov Y.S. (2005) Alexandrite. Nauka Publishers, Moscow, 144 pp.

Levine G.B. (2008) Gemology: Alexandrite-It's magic. Adornment, Vol. 7, No. 2, p. 7.

Milisenda C.C., Henn U., Henn J. (2001) New gemstone occurrences in the south-west of Madagascar. Journal of Gemmology, Vol. 27, No. 7, pp. 385-394.

Newlay S.K., Pashine J.K. (1993) A note on the finding of rare gemstone alexandrite in Madhya Pradesh. In National Seminar on Gemstones, Society of Geoscientists and Allied Technologists, Bhubaneswar, India, December 11-12, pp. 88-89.

Palke A.C., Saeseaw S., Renfro N.D., Sun Z., McClure S.F. (2019) Geographic origin determination of blue sapphire. $G \uplus G$, Vol. 55, No. 4, pp. 536-579, http://dx.doi.org/10.5741/GEMS. 55.4.536

Panjikar J., Ramchandran K.T. (1997) New chrysoberyl deposits from India. Indian Gemmologist, Vol. 7, No. 1/2, pp. 3-7.

Patnaik B.C., Nayak B.K. (1993) Alexandrite occurrence in Orissa. In National Seminar on Gemstones, Society of Geoscientists and Allied Technologists, Bhubaneswar, India, December 1112 , p. 87.

Proctor K. (1988) Chrysoberyl and alexandrite from the pegmatite districts of Minas Gerais, Brazil. Gせ)G, Vol. 24, No. 1, pp. 1632, http://dx.doi.org/10.5741/GEMS.24.1.16

Renfro N. (2015a) Digital photomicrography for gemologists. $G \uplus G$, Vol. 51, No. 2, pp. 144-159, http://dx.doi.org/ 10.5741/GEMS.51.2.144

(2015b) The application of differential interference contrast microscopy to gemmology. Journal of Gemmology, Vol. 34, No. 7, pp. 616-620.

Schmetzer K. (2010) Russian Alexandrites. Schweizerbart Science Publishers, Stuttgart, Germany, $141 \mathrm{pp}$.

(2011) Measurement and interpretation of growth patterns in chrysoberyl, including alexandrite. Journal of Gemmology, Vol. 32, No. 5-8, pp. 129-144.

Schmetzer K., Malsy A.-K. (2011a) Natural alexandrite with an irregular growth pattern: A case study. Journal of the Gemmological Association of Hong Kong, Vol. 32, pp. 68-75, http://www.gahk.org/journal/Alexandrite_for\%20web_v1.pdf

(2011b) Alexandrite and colour-change chrysoberyl from the Lake Manyara alexandrite-emerald deposit in northern Tanzania. Journal of Gemmology, Vol. 32, No. 5-8, pp. 179209.

Schmetzer K., Stocklmayer S., Stocklmayer V., Malsy A.-K. (2011) Alexandrites from the Novello alexandrite-emerald deposit, Masvingo District, Zimbabwe. Australian Gemmologist, Vol. 24, No. 6, pp. 133-147.

Soman K., Nair N.G K. (1985) Genesis of chrysoberyl in the pegmatites of southern Kerala, India. Mineralogical Magazine, Vol. 49, No. 354, pp. 733-738.

Stockton C.M., Kane R.E. (1988) The distinction of natural from synthetic alexandrite by infrared spectroscopy. $G \uplus G$, Vol. 24, No. 1, pp. 44-46, http://dx.doi.org/10.5741/GEMS.24.1.44

Sun Z., Palke A.C., Breeding C.M., Dutrow B.L. (2019) A new method for determining gem tourmaline species by LA-ICPMS. $G \uplus G$, Vol. 55, No. 1, pp. 2-17, http://dx.doi.org/ 10.5741/GEMS.55.1.2

Valentini P. (1998) Current mining report for India. ICA Gazette, pp. 8-10.

Voynick S. (1998) Cat's-eye chrysoberyl. The Guide, Vol. 17, No. 1 , pp. 13-15.

Zoysa E.G. (1987) An account of chrysoberyl-bearing pegmatite near Pattara, Sri Lanka. Journal of Gemmology, Vol. 20, No. 7/8, pp. 486-489.

Zoysa G. (2014) Geology and gem deposits of Sri Lanka. InColor, No. 27, pp. 38-41.

Zwaan P.C. (1982) Sri Lanka: The gem island. $G \uplus G$, Vol.18, No 2, pp. 62-71, http://dx.doi.org/10.5741/GEMS.18.2.62

\section{For online access to all issues of GEMS \& GEMOLOGY from 1934 to the present, visit:}

